\title{
Glass sponge grounds on the Scotian Shelf and their associated biodiversity
}

\author{
Nickolas Hawkes ${ }^{1}$, Michelle Korabik ${ }^{2}$, Lindsay Beazley ${ }^{2, *}$, Hans Tore Rapp ${ }^{1,3}$, \\ Joana R. Xavier ${ }^{1,4}$, Ellen Kenchington ${ }^{2}$
}

${ }^{1}$ Department of Biological Sciences and K.G. Jebsen Centre for Deep-Sea Research, University of Bergen, PO Box 7803 , 5020 Bergen, Norway

${ }^{2}$ Department of Fisheries and Oceans, Bedford Institute of Oceanography, Dartmouth, Nova Scotia B2Y 4A2, Canada

${ }^{3}$ NORCE, Norwegian Research Centre, NORCE Environment, Nygårdsgaten 112, 5008 Bergen, Norway

${ }^{4}$ CIIMAR - Interdisciplinary Centre of Marine and Environmental Research, University of Porto,

Terminal de Cruzeiros do Porto de Leixões, Av. General Norton de Matos s/n, 4450-208 Matosinhos, Portugal

\begin{abstract}
Emerald Basin on the Scotian Shelf off Nova Scotia, Canada, is home to a globally unique population of the glass sponge Vazella pourtalesi. Through the analysis of both in situ photographs and trawl catch data from annual multispecies bottom-trawl surveys, we examined community composition, species density, and abundance of epibenthos and fish associated with $V$. pourtalesi compared to locations without this sponge. Using generalized linear models and analysis of similarities, the importance of $V$. pourtalesi in enhancing species density and abundance of the associated epibenthic community was assessed against that of the hard substrate on which it settles. Our results indicated that the megafaunal assemblage associated with $V$. pourtalesi was significantly different in composition and higher in species density and abundance compared to locations without $V$. pourtalesi. Analysis of similarity of trawl catch data indicated that fish communities associated with the sponge grounds are significantly different from those without $V$. pourtalesi, although no species were found exclusively on the sponge grounds. Our study provides further evidence of the role played by sponge grounds in shaping community structure and biodiversity of associated deep-sea epibenthic and fish communities. The mechanism for biodiversity enhancement within the sponge grounds formed by $V$. pourtalesi is likely the combined effect of both the sponge itself and its attachment substrate, which together comprise the habitat of the sponge grounds. We also discuss the role of habitat provision between the mixed-species tetractinellid sponges of the Flemish Cap and the monospecific glass sponge grounds of Emerald Basin.
\end{abstract}

KEY WORDS: Vazella pourtalesi $\cdot$ Hexactinellida $\cdot$ Epibenthic megafauna $\cdot$ Diversity

\section{INTRODUCTION}

Sponges are recognized as ecologically important components of marine ecosystems and display a wide variety of ecosystem functions, including the provision of microhabitat, modification of substrate, bentho-pelagic coupling, and carbon and silicate sequestration (Bell 2008). Sponges are considered ecosystem engineers that can alter the environment by way of

*Corresponding author: Lindsay.Beazley@dfo-mpo.gc.ca

$\S_{\text {Corrections were made after publication. For details see }}$ www.int-res.com/articles/meps_oa/m622p231.pdf This updated version: July 18, 2019 their own morphological structures, including both living and dead tissues (Jones et al. 1994). In deeper waters, aggregations of sponges, commonly referred to as sponge grounds (Hogg et al. 2010, Knudby et al. 2013, Roberts et al. 2018) or 'ostur' (aggregations of tetractinellid sponges; Klitgaard \& Tendal 2004), are common at lower shelf, bathyal, and/or abyssal depths (Maldonado et al. 2017) where they can form extensive habitats and comprise a major portion of the

(C) Hawkes N, Rapp HT, Xavier JR and Fisheries and Oceans, Canada (2019). Open Access under Creative Commons by Attribution Licence. Use, distribution and reproduction are unrestricted. Authors and original publication must be credited.

Publisher: Inter-Research · www.int-res.com 
regional benthic biomass (up to $90 \%$, excluding fish; Klitgaard \& Tendal 2004, Murillo et al. 2012). Yet, comparatively little is known of their ecological function in these ecosystems. Several studies have noted the importance of deep-sea sponge grounds in benthic-pelagic coupling and the cycling of nutrients (Kutti et al. 2013 and reviewed by Maldonado et al. 2017). For instance, Kutti et al. (2013) estimated that a sponge ground formed by the massive demosponge Geodia barretti on the Norwegian Shelf could filter approximately 250 million $\mathrm{m}^{3}$ of water per day and consume $60 \mathrm{t}$ of carbon. Sponge grounds are also recognized as hotspots for biodiversity of invertebrates and fish (Klitgaard 1995, Freese \& Wing 2003), with the likely mechanism being the increased habitat heterogeneity provided by the sponge structures on otherwise featureless bottom types.

The association between sponge grounds and biodiversity was noted by the United Nations General Assembly resolution 61/105 adopted in 2006, which in its Annex 1A specifically lists sponge grounds as vulnerable to destructive fishing practices and calls for their protection (UNGA 2006). Despite biodiversity conservation being one of the rationales behind the call for the protection of sponge grounds, only a few studies have quantified the effect of these biogenic habitats on the diversity of associated epibenthic megafauna (e.g. Klitgaard 1995, Bo et al. 2012, Beazley et al. 2013, 2015) and fish (Freese \& Wing 2003, Marliave et al. 2009, Miller et al. 2012), and even fewer have reported on the importance of sponge ground species composition and morphology in the provision of habitat (but see Klitgaard 1995, Beazley et al. 2013). Through the analysis of in situ photographic data, Beazley et al. (2013) noted significant differences in the composition of epibenthic megafauna associated with Asconema foliatum, a thinwalled/foliose glass sponge, and both fan-shaped and papillate/globular demosponges in the Flemish Cap area (northwest Atlantic), with a greater number of echinoderms associated with the former. Similarly, the presence of spicule 'fur' commonly found on tetractinellid sponges was associated with an increased number of epifauna in sponge grounds in the northeast Atlantic (Klitgaard 1995).

Of the sponge grounds described from the northwest Atlantic, most are considered mixed-species assemblages dominated by tetractinellid sponges (Murillo et al. 2012, Beazley et al. 2013, 2015, Knudby et al. 2013). However, Beazley et al. (2018) recently described the presence of the only known monospecific sponge ground formed by the glass sponge Vazella pourtalesi (Schmidt 1870; family
Rossellidae) in Emerald Basin, a deep-water basin located on the continental shelf off Nova Scotia, Canada. These sponge grounds form the largest known monospecific aggregation of its kind and are unusual in that they occur at the shallow end of the hexactinellid distribution, from $\sim 75$ to $275 \mathrm{~m}$ (Fuller 2011). The size of individual $V$. pourtalesi sponges there reaches $110 \mathrm{~cm}$ in height and $75 \mathrm{~cm}$ in width (Fuller 2011), much larger than individuals described from other locations (Tabachnik 2002, Fuller 2011). Commonly referred to as 'Russian hats,' these sponges have a large barrel or vase-shaped morphology, which is typical of many rossellid species (Reiswig 1996). Their skeleton is made of siliceous spicules with a 'hexactine' morphology (Reiswig 2006), which often accumulates a significant amount of flocculent material on its spicules (Fuller 2011). Unlike Pheronema carpenteri and Schaudinnia rosea, other rossellid sponges that form dense aggregations in the northeast Atlantic (e.g. Rice et al. 1990, Barthel et al. 1996, Roberts et al. 2018), V. pourtalesi attaches to hard substrate, such as pebbles, cobbles, and boulders.

The invertebrates and fish associated with $V$. pourtalesi were first described by Fuller (2011) from video observations collected using a remotely operated vehicle. Ocean pout was most frequently observed within the sponge grounds, followed by redfish and hake. A high diversity of invertebrates was also noted, with observations consisting mostly of shrimp, other sponge species, rock crabs, and anemones. At the time, however, this diversity was not compared to areas outside the sponge grounds. Through the examination of both in situ photographs and trawlderived catch data from an annual multispecies bottom-trawl survey of the Scotian Shelf conducted by Fisheries and Oceans Canada (DFO), we document the diversity and abundance of epibenthic megafauna and fish associated with the monospecific sponge ground formed by $V$. pourtalesi in Emerald Basin. We compare the composition of species, diversity, and abundance of epibenthos from in situ photographs collected in areas with and without the presence of $V$. pourtalesi. Using generalized linear models (GLMs), the importance of this sponge ground in enhancing fine-scale diversity and abundance of the associated megafauna was evaluated against that of the presence (percent cover) of hard substrate, which has also been shown to enhance the diversity of local fauna in deep-sea environments (Lacharité \& Metaxas 2017). Furthermore, broader-scale associations between $V$. pourtalesi and bentho-pelagic fish and invertebrate species collected from the DFO bottom trawl surveys were examined. Finally, we com- 
pare our results with those of Beazley et al. (2013, 2015), who used similar methodologies to survey and describe the epibenthic megafauna associated with the tetractinellid sponge grounds on the slopes of the Flemish Cap, allowing for the first comparison between the diversity associated with multi- and monospecific sponge grounds and between massive and barrel-shaped morphologies. This study is the first comparative analysis of in situ epibenthic megafauna associated with the sponge grounds formed by $V$. pourtalesi and contributes to our understanding of the role of sponges in enhancing biodiversity.

\section{MATERIALS AND METHODS}

\subsection{Study area}

The Scotian Shelf is a $700 \mathrm{~km}$ long and $200 \mathrm{~km}$ wide section of continental shelf off Nova Scotia, and is bounded by the Northeast Channel to the southwest and the Laurentian Channel to the east. Emerald Basin, the location of the densest concentrations of Vazella pourtalesi (see Beazley et al. 2018), is one of the largest of a series of irregular basins located on the inner Scotian Shelf, approximately 60 nautical miles south of Halifax, Nova Scotia. It is the deepest of the basins, reaching depths of nearly $300 \mathrm{~m}$. Along with the shallower LaHave Basin, it sits at the head of the Scotian Gulf, an inlet formed by a cross-shelf channel between Emerald Bank and LaHave Bank. Beazley et al. (2018) provide a summary of the environmental conditions associated with these sponge grounds.

\subsection{Benthic imagery}

In 2011, a total of 17 photographic transects were collected in Emerald Basin using the lightweight camera tripod system 'Campod', operated from the Canadian Coast Guard Ship (CCGS) 'Hudson'. Campod is controlled via a winch on deck and collects video footage and high-resolution photographs as it drifts along the seabed at a controlled height and speed. The system was equipped with an obliquely mounted Sony SC-999 video camera to collect forward-facing video of the seabed and a vertically mounted Sony DXC-950 camera for downward video collection. Campod was also fitted with a downwardfacing, high-resolution Nikon D300 digital still camera with 2 high-speed flashes. The height of the downward-facing camera above the seabed was $\sim 1 \mathrm{~m}$ when Campod was landed. Digital still photos were taken at $\sim 1$ min intervals with Campod landed on the seabed. Campod was equipped with 2 laser beams calibrated at $10 \mathrm{~cm}$ apart that were used as a size reference in the video and photos (Beazley \& Kenchington 2015).

The video footage from all 17 transects was analyzed for $V$. pourtalesi presence and condition (whether the sponge was live or dead) in order to map its distribution and to aid delineation of the boundaries of 2 sponge conservation areas designated in 2013 by DFO to protect $V$. pourtalesi (Fig. 1) (Beazley et al. 2018). From this, photographs from 5 photo-transects were chosen for further analyses to deduce fine-scale associations between $V$. pourtalesi and the surrounding megafaunal community. Transects 18, 19, 20, and 21 are located inside the Sambro Bank Sponge Conservation Area (Fig. 1) and were chosen due to the high observed sponge densities in the video footage collected there. Transect 5 was additionally analyzed to provide information from the Emerald Basin Sponge Conservation Area. In total, 467 photographs across all 5 transects were examined. Details of the number of photos and metadata associated with each transect are given in Table 1.

\subsection{Image analysis and identification of megafauna}

Photos were first assessed for quality and consistency of height and lighting. Those that were too far or too close to the seabed, blurry photos, and those taken of the same area of seabed were not analyzed. Photos were analyzed following the photo analysis procedures documented by Beazley \& Kenchington (2015). Photos were viewed in Adobe Photoshop version CS2, and the associated taxon abundance data were recorded in a customized Microsoft Access database. Photos in each transect were analyzed in random order to reduce observer bias.

Following Beazley et al. $(2013,2015)$, photos were examined for the abundance of epibenthic megafauna, defined as both motile and non-motile organisms $>1 \mathrm{~cm}$ in size, living on or near the seafloor. All epibenthic megafauna that met this criterion were counted from each photo and identified down to the lowest possible taxonomic classification. Fine-scale features used to identify many taxa to species level were often not visible, resulting in the designation of mutually exclusive morphotypes to those megafauna that could not be identified to species (e.g. Actiniaria sp. 1 and Porifera sp. 1). Any megafauna that could 


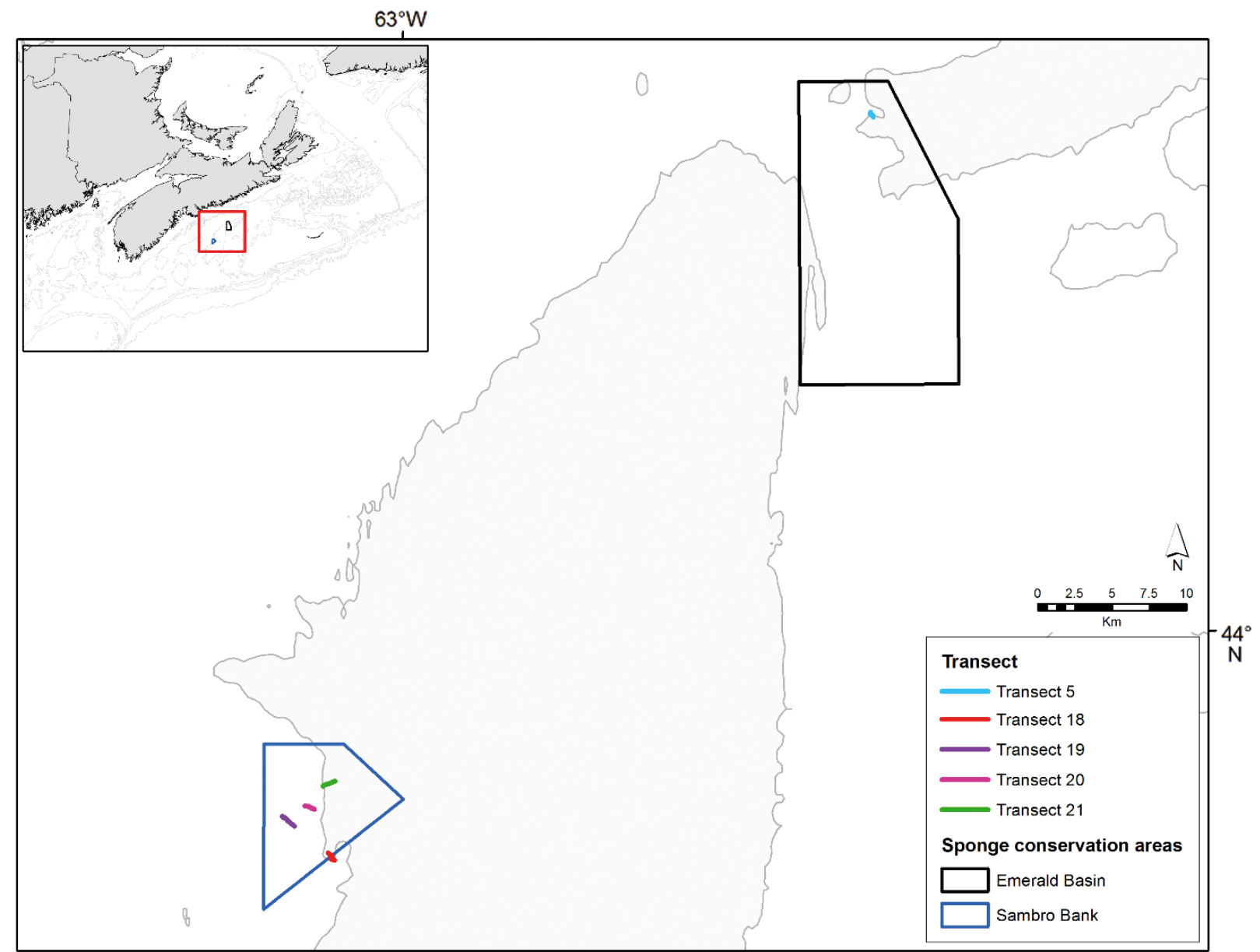

Fig. 1. Locations of the 5 Campod photo-transects collected in the Emerald Basin and Sambro Bank Sponge Conservation Areas off Nova Scotia, Canada, in 2011 . Water depths $>200 \mathrm{~m}$ are indicated by the light grey polygons

not be placed into a phylum were designated as 'Unidentified' and were separated according to overall shape and other superficial features.

Throughout the transects, both live and dead $V$. pourtalesi individuals were observed and recorded separately. Given the dominance of dead individuals over live, these were excluded from the taxon abundance data and instead used as a factor in community analyses to examine their effect on the surrounding megafaunal community. The krill Meganyctiphanes norvegica dominated the total abundance of Transects 18 and 21, accounting for over $91 \%$ of the total abundance on Transect 21. As this species undergoes diel vertical migration (Onsrud \& Kaartvedt 1998) and would therefore vary in abundance on the transects depending on time of day, it was also excluded from all community analyses. Similarly, photos where M. norvegica was so dense that it significantly im-

Table 1. Location and metadata associated with the 5 photo-transects from the Emerald Basin and Sambro Bank Sponge Conservation Areas. Total number of images examined for multivariate community analyses and their area covered is given in parentheses in the 2 final columns

\begin{tabular}{|c|c|c|c|c|c|c|c|c|}
\hline \multirow[t]{2}{*}{ Transect } & \multicolumn{2}{|c|}{ Position $\left({ }^{\circ} \mathrm{N} /{ }^{\circ} \mathrm{W}\right)$ in decimal degrees } & \multicolumn{3}{|c|}{$\longrightarrow$ Depth $(\mathrm{m})$} & \multirow{2}{*}{$\begin{array}{l}\text { Transect } \\
\text { length (m) }\end{array}$} & \multirow{2}{*}{$\begin{array}{c}\text { No. of } \\
\text { images }\end{array}$} & \multirow{2}{*}{$\begin{array}{c}\text { Total area } \\
\text { covered }\left(\mathrm{m}^{2}\right)\end{array}$} \\
\hline & Start & End & Minimum & Maximum & Mean \pm SD & & & \\
\hline 5 & $44.3136 /-62.6064$ & $44.3117 /-62.6041$ & 180.5 & 190.9 & $185.6 \pm 3.3$ & 780 & $52(52)$ & 21.3 \\
\hline 18 & $43.8628 /-63.0576$ & $43.8674 /-63.0627$ & 203.2 & 211.2 & $208.7 \pm 1.7$ & 924 & $50(35)$ & $20.5(14.4)$ \\
\hline 19 & $43.8837 /-63.0911$ & $43.8896 /-63.1012$ & 148.6 & 168.1 & $156.5 \pm 5.9$ & 1528 & $154(154)$ & 63.14 \\
\hline 20 & $43.8938 /-63.0742$ & $43.8959 /-63.0825$ & 151.4 & 173.5 & $159.2 \pm 5.7$ & 926 & $121(121)$ & 49.6 \\
\hline 21 & $43.9108 /-63.0570$ & $43.9080 /-63.0671$ & 210.0 & 226.0 & $221.0 \pm 4.6$ & 1034 & $76(66)$ & $31.2(27.1)$ \\
\hline
\end{tabular}


peded the view of the seabed were excluded, and photos that contained no megafauna were also not considered further. This eliminated nearly 40 photos, resulting in 428 photos for community analyses (Table 1).

The coverage of hard substrate from each photo was quantified using the photo-editing software GIMP v. 2.8.22 (www.gimp.org). All rocky hard substrate above $1 \mathrm{~cm}$ was outlined using the 'free select' tool and filled using the 'bucket fill' tool. The pixels occupied by hard substrate (i.e. filled areas) were counted, and percent cover was calculated by dividing pixel counts occupied by the hard substrate by total pixel count per photo, and multiplying this value by 100. The percent cover of hard substrate was categorized into arbitrarily chosen classes based on percent ranges in order to facilitate multivariate analyses to examine the effect of hard substrate on the associated megafaunal community. These categories were as follows: $0 \%$ (no hard substrate; 46 photos), $1-10 \%$ (215 photos), 10-20\% (83 photos), $20-30 \%$ (55 photos), 30-40\% (21 photos), and 41$55 \%$ (8 photos). The quantity of rocks $>1 \mathrm{~cm}$ per photo was also recorded but was not included in further analyses due to its high correlation with percent cover (Spearman's rank correlation coefficient, rho = 0.916).

The mean \pm SD area covered in the photos $(0.410 \pm$ $0.046 \mathrm{~m}^{2}$ ) was calculated by randomly selecting 50 photos across all 5 transects and measuring area using the $10 \mathrm{~cm}$ scaling lasers. Due to the low standard deviation in area covered, photos were considered to represent approximately equal sampling units, and the mean area covered was used to standardize the abundance data in each photo to abundance $\mathrm{m}^{-2}$.

\subsection{Benthic community analyses}

Multivariate analyses were conducted in PRIMER v. 6.1.16 and PERMANOVA+ v. 1.0.6 software (PRIMER-E; Clarke \& Gorley 2006). The large number of rare taxa in the dataset called for a reduction in order to focus the analyses on those taxa that were considered more abundant and reliably sampled (Clarke \& Warwick 2001). Therefore, only those taxa contributing $\geq 0.25 \%$ of the total abundance of any one transect were included in the taxon abundance by photo matrix, resulting in 54 taxa for analyses.

Analyses were conducted to examine the influence of location (transect), the presence and physical condition of $V$. pourtalesi, and the effect of hard substrate on the associated megafaunal community. In each case, the reduced taxon abundance matrix was $\log _{10}(x+1)$ transformed and the Bray-Curtis similarity calculated. A 1-way analysis of similarities (ANOSIM) was used to test for significant differences in the megafaunal assemblages between transects and categories of hard substrate. Here, records of $V$. pourtalesi were included in the taxon abundance matrix, but were later excluded and used as a factor in the analyses testing for the effect of $V$. pourtalesi on the associated community. Non-metric multidimensional scaling (MDS) of Bray-Curtis similarity measures using Kruskal fit scheme 1 was used to visualize potential differences in community composition between photos grouped by each factor. The 'subset MDS' function was used to generate an MDS plot on subsets of highly clustered photos.

In order to ascertain whether the physical condition (i.e. live or dead) of $V$. pourtalesi had an effect on the composition of associated megafauna, photos were categorized based on whether they had only live $V$. pourtalesi, only dead, or a mix of both. ANOSIM was used to test for significant differences in megafaunal community composition between the different states (live V. pourtalesi; 84 photos; dead: 80 photos; mix: 132 photos) and areas without $V$. pourtalesi (132 photos). Taxa driving any observed differences in community composition between treatments within factors as identified in ANOSIM were examined using the similarity percentages (SIMPER) routine in PRIMER. Given the negligible differences in the assemblages associated with the live and mixed states $(R=0.051$, see Table 2$)$, photos from these 2 categories were combined (216 photos) and used to indicate presence of live V. pourtalesi (factor referred to as 'Vazella Presence/Absence' hereafter) in further analyses to test the influence of $V$. pourtalesi on community composition and diversity as described below.

Given the possibility of interactions between the presence of $V$. pourtalesi, the hard substrate on which it attaches, and location (transect), a 3-factor permutational multivariate analysis of variance (PERMANOVA) was used to test for their influence on community composition of the associated fauna. All 3 factors were considered fixed in the analysis. Permutated pairwise tests of significant factors were conducted, and statistical significance was evaluated using a Bonferroni-adjusted significance level for multiple tests, $\alpha^{\prime}=\alpha / k$, where $k$ is the number of pairwise groups tested, and $\alpha$ is the 0.05 significance level. Non-significant terms were iteratively removed until none remained in the final result. 


\subsection{Effect of $V$. pourtalesi and hard substrate on species density and abundance of associated megafauna}

Given that samples in our study are of a fixed unit of effort (mean area per photo: $0.410 \pm 0.046 \mathrm{~m}^{2}$ ), any measure of the number of species per sample is considered a species density and therefore is expressed as the number of discrete species per unit of sampling effort (see Gotelli \& Colwell 2011; summarized by Kenchington \& Kenchington 2013). Species density, along with the total abundance of megafauna per photo, were derived from the full taxonomic dataset (94 taxa excluding V. pourtalesi) for use in hypothesis-testing methods to examine the influence of $V$. pourtalesi presence (Vazella Presence/Absence), location (Transect), and the Percent Cover of Hard Substrate on the associated megafaunal community. Using the $\mathrm{R}$ statistical software program (version 3.3.1, R Core Team 2016), both metrics were tested for normality and equality of variances between photos with and without live $V$. pourtalesi present using the Shapiro-Wilk and Levene tests, respectively. After all datasets failed to meet 1 or both assumptions, the non-parametric Wilcoxon rank sum test was applied to test for significant differences between photos with and without $V$. pourtalesi present. GLMs were then used to further explore the relationships between the response variables and covariates, and their potential interactions.

Prior to constructing GLMs, species density and the total abundance of megafauna per photo were assessed for non-spatial dependence (i.e. spatial autocorrelation). In deep-water megafaunal communities, spatial dependence has been attributed to a correlation with habitat features that vary as a function of length scale (Schneider et al. 1987). Spatial dependence amongst observations can result in reduced degrees of freedom or effective sample size and thus an increased probability of committing a type 1 error in classical hypothesis testing (Legendre et al. 2002, Kühn 2007). Autocorrelation in the species density and abundance metrics for each photo was examined per transect using Moran's I correlograms, computed using the 'correlog' function in package ' $n c f$ ' in R. Moran's $I$ is a measure of autocorrelation against distance that indicates whether the pattern in a quantitative variable is clustered, dispersed, or random in space. Moran's I ranges from -1 to +1 , where negative values indicate negative spatial autocorrelation (indicating in this example, that neighboring photos have dissimilar values of diversity and abundance), positive values indicate positive autocorrelation (i.e. neighboring photos have similar values of diversity and abundance, i.e. clustering), and values near 0 indicate no autocorrelation (Fortin \& Dale 2005). Significance of the Moran's I correlation coefficients at each distance class was assessed by computing 1000 permutations using the 'resamp' argument in the 'correlog' function in R. Correlograms were considered globally significant if at least one correlation coefficient was significant at the Bonferroni-adjusted significance level, $\alpha^{\prime}=\alpha / k$, where $k$ is the number of distance classes, and $\alpha$ is the 0.05 significance level (Legendre \& Legendre 1998, Fortin \& Dale 2005).

For most transects, Moran's I correlation coefficients were small for the species density and abundance metrics (see Fig. S1 in the Supplement at www.int-res.com/articles/suppl/m614p091_supp.pdf), although some patterns by distance class emerged. Both Transects 18 and 20 showed negative spatial autocorrelation in species density and total abundance at the largest distance classes. Spatial autocorrelation in species density was highest at the smallest distance class on Transect 19. Nonetheless, no correlograms were globally significant at the $\alpha^{\prime}$ level, indicating that the assumption of the (spatial) independence of samples was met.

GLMs were fitted to the species density and total abundance data in R, with Vazella Presence/Absence, Transect, Percent Cover of Hard Substrate, and their interaction terms as covariates. The species density data were fitted with a Poisson distribution and log link. Dispersion $(\varphi)$ in the residuals of this Poisson model was tested by dividing the generalized Pearson statistic $\chi^{2}$ (squared sum of the Pearson residuals) by the residual degrees of freedom (Zuur et al. 2009). Over- or underdispersion existed if $\varphi$ was greater or less than 1, respectively. Underdispersion was detected $(\varphi=0.73)$ in this model; however, since this phenomenon results in conservatism in $p$-values (i.e. reduced type I error; Zuur et al. 2009) the model was left as is. The abundance data were initially fitted with a Poisson distribution and log link function after the values were rounded to the nearest integer, but after overdispersion was identified $(\varphi=9.17)$, a negative binomial model with a log link function was applied (Zuur et al. 2009). The dispersion parameter of this negative binomial model was within acceptable levels $(\varphi=1.20)$.

Following Zuur et al. (2009), models were examined for non-significant terms using the 'drop1' function with a chi-squared test. All terms were significant, and so the models were not simplified further. The fit of each model was evaluated through examination of the diagnostic plots generated by the 'glm.diag.plots' 
function of package 'boot' in R (see plots in Fig. S2). Analysis of deviance tables were generated for each model to examine the amount of deviance explained by the full model and its individual terms.

Several photos contained hard substrate not colonized by $V$. pourtalesi, which allowed for further analyses to isolate the effects of both factors and their influence on species density and abundance. Welch's ANOVA was used to test for significant differences in megafaunal species density and abundance between photos with $V$. pourtalesi present (216 photos) on hard substrate, photos without $V$. pourtalesi but with hard substrate (92 photos), and photos taken of soft bottom habitat without hard substrate or $V$. pourtalesi (40 photos). Photos of hard substrate only and soft bottom were interspersed throughout the sponge grounds. SIMPER was used to identify any taxa contributing to the dissimilarity between the 3 groups.

\subsection{Broad-scale associations of trawl-caught fish and megafaunal invertebrates with $V \cdot$ pourtalesi}

Fish and invertebrate catch from the DFO annual research vessel trawl surveys on the Scotian Shelf and Gulf of Maine was examined to ascertain whether the composition of fauna was different between catches inside and outside the sponge grounds. Surveys were conducted on the CCGS 'Alfred Needler' or CCGS 'Teleost' using a Western II-A bottom trawl gear with a $19 \mathrm{~mm}$ mesh lining in the cod-end (Tremblay et al. 2007). Fishing stations were allocated using a stratified random sampling design (Chadwick et al. 2007) and conducted with standardized 30 min bottom tows at a vessel speed of approximately 3.5 knots. All fish and invertebrate catch retained on the net was sorted by taxa and counted and weighed at sea. We selected invertebrate and fish abundance data from 246 trawl sets collected between 2007 and 2017 within the area known as the Scotian Gulf, which is formed by a cross-shelf channel that opens into Emerald and LaHave Basins on the inner Scotian Shelf. This area is consistent with that predicted as suitable habitat for $V$. pourtalesi using species distribution models (see Beazley et al. 2018) and was selected to ensure that comparisons were made using fish assemblages from a similar depth range. Of those 246 sets, 79 recorded V. pourtalesi in the catch, while 167 were within the predicted habitat of $V$. pourtalesi, but had no $V$. pourtalesi in the catch. The mean \pm SD depth of the trawl sets was $202 \pm 119 \mathrm{~m}$. The location of the start positions of the selected trawl sets are shown in Fig. S3.
Catch composition for the selected data included 178 taxa. In order to reduce the effects of recording bias and anomalous catches over the $10 \mathrm{yr}$ period, we removed any taxon that was not recorded in at least 8 of the 10 years. This reduced the number of taxa to 50 , creating a 50 taxa $\times 246$ trawl sets data matrix for analysis that represents the typical species composition of the catches in the area.

A $\log _{10}(x+1)$ transformed abundance data matrix was constructed in PRIMER from the trawl survey data. A Bray-Curtis similarity matrix was generated from this matrix and an ANOSIM using a 2-way crossed design (Vazella Presence/Absence, Year) was performed to test for the effects of both factors on the contributions of the species to the total community. SIMPER analysis was performed on the Vazella Presence/Absence factor to break down the contribution of each species to the observed community similarity (and dissimilarity) between samples within/ between groups.

\section{RESULTS}

\subsection{In situ epibenthic megafauna}

A total of 7468 individuals (18 202 when standardized to $\mathrm{m}^{-2}$ ) representing 95 different taxa/morphotypes were recorded from the 428 analyzed photos across all 5 transects (see Table S1). We observed 77 taxa from 9 phyla (Annelida, Arthropoda, Bryozoa, Chordata, Cnidaria, Echinodermata, Mollusca, Nemertea, and Porifera), of which 19 were identified to species level or putative species (indicated by the 'cf.' designation) and 4 to genus. The remaining 18 taxa were unique, unidentified morphotypes. The Cnidaria, Porifera, and unidentified morphotypes were the most abundant and diverse, representing 38,25 , and $17 \%$ of the total abundance and 13,33 , and $19 \%$ of the observed taxa, respectively.

The Cnidaria were highly skewed towards a few, very abundant anemone-like species/morphotypes belonging to the orders Actiniaria and Zoantharia. No soft corals or gorgonian-type corals were observed on the transects, although juveniles of the sea pen Pennatula aculeata and the scleractinian cup coral Flabellum macandrewi were observed in low densities. Echinoderms, while uncommon, were a fairly diverse group composed of 7 different taxa. Of those, 3 were sea stars from the genera Henricia and Pteraster, 1 was a stalked crinoid (Conocrinus lofotensis), and the remainder were brittle stars. Two ophiuroid species were positively identified (Ophio- 

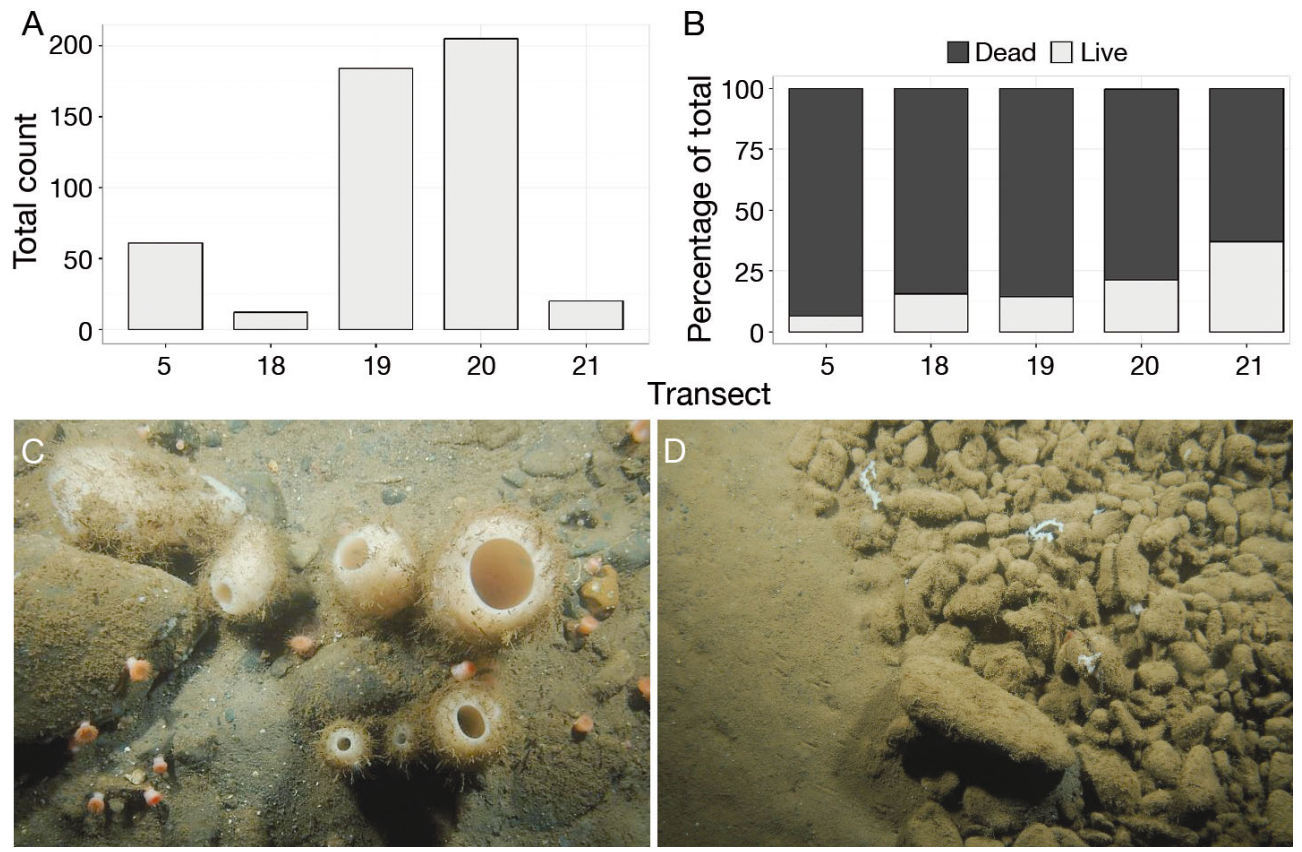

Fig. 2. (A) Total number of live Vazella pourtalesi per transect $(5,18,19,20,21)$. (B) Contribution (percentage of total) of live and dead $V$. pourtalesi to its total abundance on each transect. Examples of $V$. pourtalesi: (C) live, (D) dead. All sediment-covered structures on the right side of the image in (D) represent skeletons of $V$. pourtalesi

pholis aculeata and Ophiacantha bidentata), and a combined group consisting of both species (Ophiopholis aculeata/Ophiacantha bidentata) was also designated when the 2 could not be distinctly separated from one another. These species were small $(<2 \mathrm{~cm})$ and found on both soft sediment and as epifauna on Vazella pourtalesi. The taxa/morphotypes used in multivariate community analyses (i.e. those that comprised $\geq 0.25 \%$ abundance on any one transect) are indicated by an asterisk in Table S1. Of these 54 taxa (53 excluding V. pourtalesi), anemones (Actiniaria spp.), Unidentified 33, and serpulid worms (Serpulidae spp.) had the highest abundances.

Within the phylum Porifera, encrusting sponges on rocks and boulders dominated the diversity. Nonencrusting sponges included the stalked tulip sponge Stylocordyla borealis, globular sponges Polymastia andrica and Polymastia cf. uberrima, and several upright, branching/repent (morphologies as described by Boury-Esnault \& Rützler 1997) species of unknown identity. Live and dead $V$. pourtalesi individuals were observed on all 5 transects, in $69 \%$ of the photos included in community analyses (296 of 428 photos), and was the fifth most abundant taxon overall (Table S1). Live $V$. pourtalesi were most common on Transects 19 and 20, with nearly 200 individuals on each (Fig. 2A). Dead V. pourtalesi contributed to the majority of the total abundance of this species on every transect (Fig. 2B). Fig. 2C,D shows examples of both live and dead $V$. pourtalesi. The dead sponge was often observed in dense aggregations on soft sediment.
ANOSIM indicated significant differences in community composition between transects (global $\mathrm{R}=$ $0.243, \mathrm{p}<0.001$ ), with the largest pairwise dissimilarity occurring between Transects 5 and $18(\mathrm{R}=0.581$, $\mathrm{p}<0.001)$, followed by Transects 20 and $21(\mathrm{R}=$ $0.417, \mathrm{p}<0.001)$. The overlap in community composition between transects was further visualized in the MDS plot (Fig. 3). Transects 18 and 21 showed a higher variability in abundance-based community structure compared to the other transects. No differences in community composition between Transect 5 located in the Emerald Basin Sponge Conservation Area and the combined taxon abundance data from the 4 transects located in the Sambro Bank Sponge Conservation Area were apparent, suggesting a common sponge ground community throughout Emerald Basin.

\subsection{Influence of $V$. pourtalesi and hard substrate on epibenthic megafaunal composition}

Significantly different megafaunal assemblages were associated with the different physical states of $V$. pourtalesi (i.e. live vs. dead vs. mixed states vs. photos in which $V$. pourtalesi was absent; Table 2). The strongest pairwise dissimilarity occurred between the mixed and absent categories $(\mathrm{R}=0.304)$, followed by mixed and dead categories $(\mathrm{R}=0.174)$. The taxa that contributed to this dissimilarity are shown in Table 3. The highest average dissimilarity was indicated between the mixed and absent categories (82.05\%), fol- 


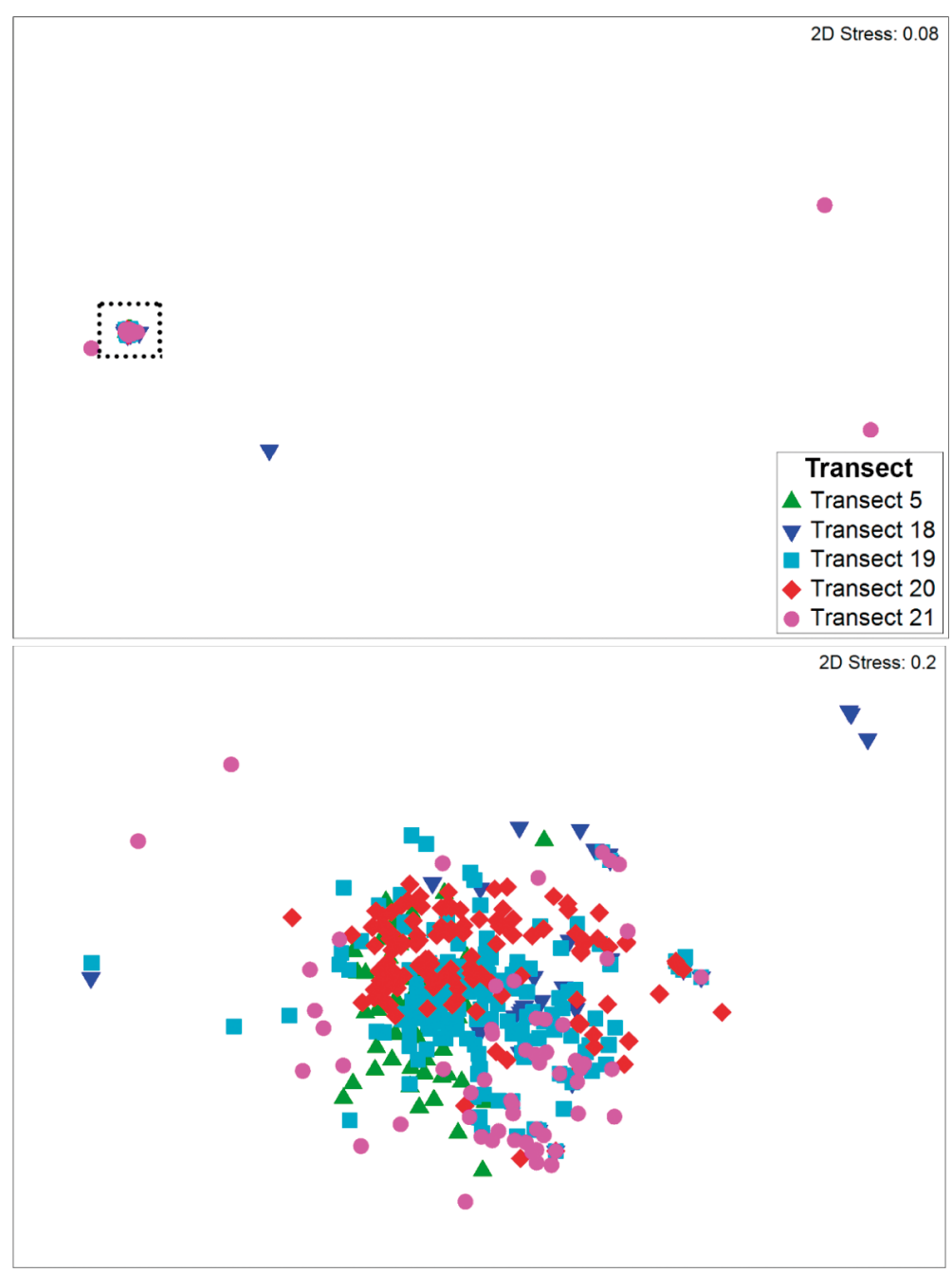

Fig. 3. Multidimensional scaling (MDS) plot based on Bray-Curtis similarity of transformed abundance $\left(\log _{10}(x+1)\right)$ of taxa comprising $\geq 0.25 \%$ abundance on any one transect, labeled by transect. (A) All samples. (B) Plot generated from a subset of samples selected from the tight cluster of photos within the black dashed box in (A) (note the higher stress of 0.2 ) pourtalesi. No organism was associated exclusively with dead $V$. pourtalesi.

PERMANOVA identified significant effects of Transect, Vazella Presence/ Absence (i.e. live and mixed states combined vs. absent), and the categorical representation of Hard Substrate Cover (Table 4) after the removal of nonsignificant interaction terms. The 2-way interactions between Transect and Vazella Presence/Absence, and Transect and Hard Substrate Cover were also significant, while the interaction between all 3 terms was non-significant, as well as the interaction between the presence of $V$. pourtalesi and Hard Substrate Cover. The effect of Hard Substrate Cover explained the largest proportion of the variance, followed by Transect.

\subsection{Influence of $V$. pourtalesi and hard substrate on epibenthic megafaunal species density and abundance}

Species density and the total abundance of megafauna per photo significantly differed between photos with and without $V$. pourtalesi present (species density: $W=3063.50, \mathrm{p}<0.001$; total abundance: $W=2682.00, \mathrm{p}<0.001$, where 'present' indicates both live and mixed states combined). Both metrics were higher in the presence of $V$. pourtalesi (mean \pm SE: species density: $7.06 \pm$ 0.21 ; total abundance: $56.07 \pm 2.67$ ) than absence (species density: $2.71 \pm 0.17$; total abundance: $13.28 \pm 1.22$ ). lowed by the live and absent categories $(80.54 \%)$. Of the 10 taxa contributing to $\sim 70 \%$ dissimilarity between mixed and absent categories, only 1 taxon, Zoanthidae spp., was higher in areas without $V$. pourtalesi. This taxon was often observed in patches on soft substrates, explaining its greater affiliation with the absent category. The remaining 9 taxa were typically associated with hard substrate: anemones (Actiniaria spp., and Actiniaria sp. 9), encrusting polychaetes of the family Serpulidae, encrusting sponges Porifera sp. 4 and Hymedesmiidae sp. 4, and bivalves of the family Anomiidae. Unidentified 33 was most often observed in close proximity to both live and dead $V$. pourtalesi, and Unidentified 22, an epifaunal tubular organism, was observed exclusively on live $V$.
Table 2. One-way analysis of similarities (ANOSIM) testing the hypothesis of no significant difference in community composition between photos with live, dead, mixed, and no Vazella pourtalesi

\begin{tabular}{lcc}
$\begin{array}{l}\text { Global test: } \mathrm{R}=0.163, \mathrm{p}=0.001 \\
\text { Pairwise comparison }\end{array}$ & $\mathrm{R}$ & $\mathrm{p}$ \\
\hline Live Vazella vs. Dead & 0.120 & 0.001 \\
Live Vazella vs. Mixed & 0.051 & 0.005 \\
Live Vazella vs. Absent & 0.139 & 0.001 \\
Dead Vazella vs. Mixed & 0.174 & 0.001 \\
Dead Vazella vs. Absent & 0.036 & 0.029 \\
Mixed Vazella vs. Absent & 0.304 & 0.001 \\
\hline
\end{tabular}


Table 3. Similarity percentage (SIMPER) identifying the taxa that contributed to $70 \%$ of the dissimilarity between photos with live (L), dead (D), mixed (M), and no Vazella pourtalesi (absent, A) based on the $\log (x+1)$ transformed taxon abundance matrix. Average dissimilarity L/A $=80.54 \%, \mathrm{~L} / \mathrm{D}=73.07 \%, \mathrm{~L} / \mathrm{M}=67.39 \%, \mathrm{D} / \mathrm{M}=71.79 \%, \mathrm{D} / \mathrm{A}=77.50 \%$, and $\mathrm{M} / \mathrm{A}=82.05 \%$

\begin{tabular}{|c|c|c|c|c|c|c|}
\hline $\begin{array}{l}\text { Groups com- } \\
\text { pared }(1 / 2)\end{array}$ & Taxon & \multicolumn{2}{|c|}{ Average abundance } & $\begin{array}{c}\text { Average } \\
\text { dissimilarity }\end{array}$ & $\begin{array}{c}\text { Contribution } \\
(\%)\end{array}$ & $\begin{array}{c}\text { Cumulative } \\
\text { contribution (\%) }\end{array}$ \\
\hline $\mathrm{L} / \mathrm{A}$ & Actiniaria spp. & 2.16 & 0.46 & 14.31 & 17.76 & 17.76 \\
\hline $\mathrm{L} / \mathrm{A}$ & Unidentified 33 & 1.16 & 0.87 & 8.62 & 10.71 & 28.47 \\
\hline L/A & Serpulidae spp. & 1.05 & 0.43 & 8.25 & 10.24 & 38.71 \\
\hline $\mathrm{L} / \mathrm{A}$ & Zoanthidae spp. & 0.70 & 0.66 & 7.59 & 9.43 & 48.13 \\
\hline $\mathrm{L} / \mathrm{A}$ & Malacostraca spp. & 0.58 & 0.51 & 5.57 & 6.92 & 55.05 \\
\hline $\mathrm{L} / \mathrm{A}$ & Unidentified 22 & 0.76 & 0.00 & 5.32 & 6.60 & 61.66 \\
\hline $\mathrm{L} / \mathrm{A}$ & Anomiidae sp. 1 & 0.73 & 0.13 & 4.30 & 5.34 & 67.00 \\
\hline $\mathrm{L} / \mathrm{A}$ & Porifera sp. 4 & 0.60 & 0.09 & 3.63 & 4.51 & 71.51 \\
\hline $\mathrm{L} / \mathrm{D}$ & Actiniaria spp. & 2.16 & 1.16 & 10.05 & 13.75 & 13.75 \\
\hline $\mathrm{L} / \mathrm{D}$ & Unidentified 33 & 1.16 & 1.67 & 7.56 & 10.35 & 24.10 \\
\hline $\mathrm{L} / \mathrm{D}$ & Serpulidae spp. & 1.05 & 0.94 & 6.86 & 9.39 & 33.48 \\
\hline $\mathrm{L} / \mathrm{D}$ & Zoanthidae spp. & 0.70 & 0.81 & 6.28 & 8.59 & 42.08 \\
\hline $\mathrm{L} / \mathrm{D}$ & Porifera sp. 4 & 0.60 & 0.54 & 4.07 & 5.56 & 47.64 \\
\hline $\mathrm{L} / \mathrm{D}$ & Unidentified 22 & 0.76 & 0.00 & 4.03 & 5.51 & 53.15 \\
\hline $\mathrm{L} / \mathrm{D}$ & Malacostraca spp. & 0.58 & 0.54 & 3.93 & 5.38 & 58.53 \\
\hline $\mathrm{L} / \mathrm{D}$ & Anomiidae sp. 1 & 0.73 & 0.37 & 3.89 & 5.32 & 63.85 \\
\hline $\mathrm{L} / \mathrm{D}$ & Actiniaria sp. 9 & 0.12 & 0.64 & 3.48 & 4.76 & 68.61 \\
\hline $\mathrm{L} / \mathrm{D}$ & Hymedesmiidae sp. 4 & 0.47 & 0.29 & 2.75 & 3.76 & 72.37 \\
\hline $\mathrm{L} / \mathrm{M}$ & Actiniaria spp. & 2.16 & 2.27 & 7.45 & 11.05 & 11.05 \\
\hline $\mathrm{L} / \mathrm{M}$ & Unidentified 33 & 1.16 & 1.44 & 5.70 & 8.46 & 19.51 \\
\hline $\mathrm{L} / \mathrm{M}$ & Serpulidae spp. & 1.05 & 1.25 & 5.40 & 8.02 & 27.53 \\
\hline $\mathrm{L} / \mathrm{M}$ & Anomiidae sp. 1 & 0.73 & 0.88 & 4.20 & 6.23 & 33.76 \\
\hline $\mathrm{L} / \mathrm{M}$ & Unidentified 22 & 0.76 & 0.66 & 4.10 & 6.09 & 39.85 \\
\hline $\mathrm{L} / \mathrm{M}$ & Porifera sp. 4 & 0.60 & 0.93 & 4.10 & 6.09 & 45.94 \\
\hline $\mathrm{L} / \mathrm{M}$ & Zoanthidae spp. & 0.70 & 0.44 & 4.06 & 6.04 & 51.97 \\
\hline $\mathrm{L} / \mathrm{M}$ & Hymedesmiidae sp. 4 & 0.47 & 0.84 & 3.75 & 5.57 & 57.54 \\
\hline $\mathrm{L} / \mathrm{M}$ & Malacostraca spp. & 0.58 & 0.67 & 3.47 & 5.14 & 62.69 \\
\hline $\mathrm{L} / \mathrm{M}$ & Actiniaria sp. 9 & 0.12 & 0.55 & 2.49 & 3.69 & 66.38 \\
\hline $\mathrm{L} / \mathrm{M}$ & Hymedesmiidae sp. 1 & 0.14 & 0.44 & 1.75 & 2.60 & 68.98 \\
\hline $\mathrm{L} / \mathrm{M}$ & Porifera sp. 22 & 0.15 & 0.28 & 1.55 & 2.30 & 71.29 \\
\hline $\mathrm{D} / \mathrm{M}$ & Actiniaria spp. & 1.16 & 2.27 & 8.55 & 11.91 & 11.91 \\
\hline $\mathrm{D} / \mathrm{M}$ & Unidentified 33 & 1.67 & 1.44 & 6.22 & 8.66 & 20.57 \\
\hline $\mathrm{D} / \mathrm{M}$ & Serpulidae spp. & 0.94 & 1.25 & 5.79 & 8.06 & 28.63 \\
\hline $\mathrm{D} / \mathrm{M}$ & Zoanthidae spp. & 0.81 & 0.44 & 4.79 & 6.67 & 35.30 \\
\hline $\mathrm{D} / \mathrm{M}$ & Porifera sp. 4 & 0.54 & 0.93 & 4.31 & 6.01 & 41.31 \\
\hline $\mathrm{D} / \mathrm{M}$ & Actiniaria sp. 9 & 0.64 & 0.55 & 4.10 & 5.71 & 47.01 \\
\hline $\mathrm{D} / \mathrm{M}$ & Anomiidae sp. 1 & 0.37 & 0.88 & 3.96 & 5.51 & 52.52 \\
\hline $\mathrm{D} / \mathrm{M}$ & Hymedesmiidae sp. 4 & 0.29 & 0.84 & 3.64 & 5.07 & 57.59 \\
\hline $\mathrm{D} / \mathrm{M}$ & Malacostraca spp. & 0.54 & 0.67 & 3.58 & 4.98 & 62.58 \\
\hline $\mathrm{D} / \mathrm{M}$ & Unidentified 22 & 0.00 & 0.66 & 2.91 & 4.05 & 66.63 \\
\hline $\mathrm{D} / \mathrm{M}$ & Hymedesmiidae sp. 5 & 0.20 & 0.32 & 1.79 & 2.49 & 69.12 \\
\hline $\mathrm{D} / \mathrm{M}$ & Porifera sp. 22 & 0.18 & 0.28 & 1.68 & 2.33 & 71.45 \\
\hline $\mathrm{D} / \mathrm{A}$ & Unidentified 33 & 1.67 & 0.87 & 11.99 & 15.48 & 15.48 \\
\hline $\mathrm{D} / \mathrm{A}$ & Zoanthidae spp. & 0.81 & 0.66 & 9.14 & 11.79 & 27.27 \\
\hline $\mathrm{D} / \mathrm{A}$ & Actiniaria spp. & 1.16 & 0.46 & 8.68 & 11.21 & 38.47 \\
\hline $\mathrm{D} / \mathrm{A}$ & Serpulidae spp. & 0.94 & 0.43 & 7.67 & 9.90 & 48.37 \\
\hline $\mathrm{D} / \mathrm{A}$ & Malacostraca spp. & 0.54 & 0.51 & 5.78 & 7.46 & 55.84 \\
\hline $\mathrm{D} / \mathrm{A}$ & Actiniaria sp. 9 & 0.64 & 0.06 & 4.80 & 6.20 & 62.04 \\
\hline $\mathrm{D} / \mathrm{A}$ & Porifera sp. 4 & 0.54 & 0.09 & 4.04 & 5.21 & 67.25 \\
\hline $\mathrm{D} / \mathrm{A}$ & Anomiidae sp. 1 & 0.37 & 0.13 & 2.67 & 3.45 & 70.70 \\
\hline $\mathrm{M} / \mathrm{A}$ & Actiniaria spp. & 2.27 & 0.46 & 12.33 & 15.04 & 15.04 \\
\hline $\mathrm{M} / \mathrm{A}$ & Unidentified 33 & 1.44 & 0.87 & 7.93 & 9.67 & 24.71 \\
\hline $\mathrm{M} / \mathrm{A}$ & Serpulidae spp. & 1.25 & 0.43 & 6.89 & 8.40 & 33.11 \\
\hline $\mathrm{M} / \mathrm{A}$ & Zoanthidae spp. & 0.44 & 0.66 & 5.35 & 6.52 & 39.63 \\
\hline $\mathrm{M} / \mathrm{A}$ & Malacostraca spp. & 0.67 & 0.51 & 4.74 & 5.78 & 45.41 \\
\hline $\mathrm{M} / \mathrm{A}$ & Porifera sp. 4 & 0.93 & 0.09 & 4.71 & 5.74 & 51.15 \\
\hline $\mathrm{M} / \mathrm{A}$ & Anomiidae sp. 1 & 0.88 & 0.13 & 4.59 & 5.60 & 56.75 \\
\hline $\mathrm{M} / \mathrm{A}$ & Hymedesmiidae sp. 4 & 0.84 & 0.04 & 4.12 & 5.03 & 61.77 \\
\hline $\mathrm{M} / \mathrm{A}$ & Unidentified 22 & 0.66 & 0.00 & 3.66 & 4.46 & 66.23 \\
\hline $\mathrm{M} / \mathrm{A}$ & Actiniaria sp. 9 & 0.55 & 0.06 & 3.12 & 3.81 & 70.04 \\
\hline
\end{tabular}


Table 4. Three-factor permutational multivariate analysis of variance (PERMANOVA) examining effects of Transect, Vazella Presence/Absence, and categorical Hard Substrate Cover on benthic community composition. SS: sum of squares; MS: mean square. Values in parentheses in the last column indicate the square root of the Estimate of Variance Component

\begin{tabular}{|c|c|c|c|c|c|c|}
\hline Term & df & SS & MS & Pseudo- $F$ & $\begin{array}{c}\text { Permutated } \\
\text { p-value }\end{array}$ & $\begin{array}{c}\text { Estimate of } \\
\text { Variance Component } \\
\text { (sq. root) }\end{array}$ \\
\hline Transect & 4 & 26375.00 & 6593.60 & 3.129 & 0.001 & 328.15 (18.12) \\
\hline Vazella Presence/Absence & 1 & 6222.10 & 622.10 & 2.953 & 0.005 & $99.90(9.99)$ \\
\hline Hard Substrate & 6 & 40161.00 & 6693.40 & 3.176 & 0.001 & $348.54(18.67)$ \\
\hline Transect $\times$ Vazella Presence/Absence & 4 & 17318.00 & 4329.40 & 2.055 & 0.003 & $139.76(11.82)$ \\
\hline Transect $\times$ Hard Substrate & 17 & 51533.00 & 3031.40 & 1.439 & 0.004 & $122.69(11.08)$ \\
\hline Residuals & 315 & $6.638 \times 10^{-5}$ & 2107.30 & & & $2107.30(45.91)$ \\
\hline Total & 347 & $1.046 \times 10^{-6}$ & & & & \\
\hline
\end{tabular}

GLMs fitted to the species density and total abundance data behaved similarly in terms of total deviance explained and the importance of the individual explanatory variables (Table 5). The species density and total abundance models explained 68 and $71 \%$ of the total deviance in the data, respectively, with Vazella Presence/Absence accounting for $41 \%$ in each model. Percent Cover of Hard Substrate, followed by Transect, were the next most important variables. Most interaction terms between variables were significant, although no one term explained more than $2 \%$ of the deviance in the data. The pattern of higher diversity and abundance of megafauna between photos with $V$. pourtalesi pres- ent was consistent across all 5 transects (Fig. 4). However, those transects supporting an overall higher diversity and abundance of megafauna typically also had a higher mean percent cover of hard substrate (Fig. 4).

Mean species density and abundance of megafauna was statistically significant between photos with $V$. pourtalesi present on hard substrate, photos with hard substrate only, and photos of soft sediment only (Welch's ANOVA; species density: $F=204.09$, $\mathrm{p}<0.001$; abundance: $F=140.59, \mathrm{p}<0.001$ ). Photos with $V$. pourtalesi present on hard substrate had a higher diversity and abundance of megafauna than photos of hard substrate and no V. pourtalesi, sug-

Table 5. Analysis of deviance results of generalized linear models testing the influence of Vazella Presence/Absence, Transect, and Percent Cover of Hard Substrate on megafaunal species density and total abundance per photo. Asterisks mark significant $(p<0.05)$ values

\begin{tabular}{|c|c|c|c|c|}
\hline Model term & $\begin{array}{l}\text { Explained } \\
\text { deviance }\end{array}$ & $\begin{array}{l}\text { Residual } \\
\text { deviance }\end{array}$ & \% Explained & $\operatorname{Pr}(>$ Chi $)$ \\
\hline \multicolumn{5}{|l|}{ Species density } \\
\hline NULL & & 773.51 & & \\
\hline Vazella Presence/Absence & 316.39 & 457.12 & 41 & $<0.001^{*}$ \\
\hline Transect & 39.64 & 417.47 & 5 & $<0.001^{*}$ \\
\hline Percent Cover of Hard Substrate & 142.56 & 274.92 & 18 & $<0.001^{*}$ \\
\hline Vazella Presence/Absence $\times$ Transect & 8.17 & 266.75 & 1 & 0.086 \\
\hline Vazella Presence/Absence $\times$ Percent Cover Hard Substrate & 7.01 & 259.74 & 1 & $0.008^{*}$ \\
\hline Transect x Percent Cover of Hard Substrate & 6.82 & 252.91 & 1 & 0.145 \\
\hline $\begin{array}{l}\text { Vazella Presence/Absence } \times \text { Transect } \times \text { Percent Cover Hard Substrate } \\
\text { Total deviance explained }\end{array}$ & 9.58 & 243.33 & $\begin{array}{c}1 \\
68\end{array}$ & $0.048^{*}$ \\
\hline \multicolumn{5}{|l|}{ Total abundance } \\
\hline NULL & & 1283.53 & & \\
\hline Vazella Presence/Absence & 531.66 & 751.87 & 41 & $<0.001^{*}$ \\
\hline Transect & 142.93 & 608.94 & 11 & $<0.001^{*}$ \\
\hline Percent Cover of Hard Substrate & 177.88 & 431.07 & 14 & $<0.001^{*}$ \\
\hline Vazella Presence/Absence $\times$ Transect & 28.49 & 402.57 & 2 & $<0.001^{*}$ \\
\hline Vazella Presence/Absence $\times$ Percent Cover Hard Substrate & 9.69 & 392.89 & 1 & $<0.001^{*}$ \\
\hline Transect x Percent Cover of Hard Substrate & 12.05 & 380.84 & 1 & $<0.001^{*}$ \\
\hline Vazella Presence/Absence $\times$ Transect $\times$ Percent Cover Hard Substrate & 11.46 & 369.38 & 1 & $<0.001^{*}$ \\
\hline Total deviance explained & & & 71 & \\
\hline
\end{tabular}



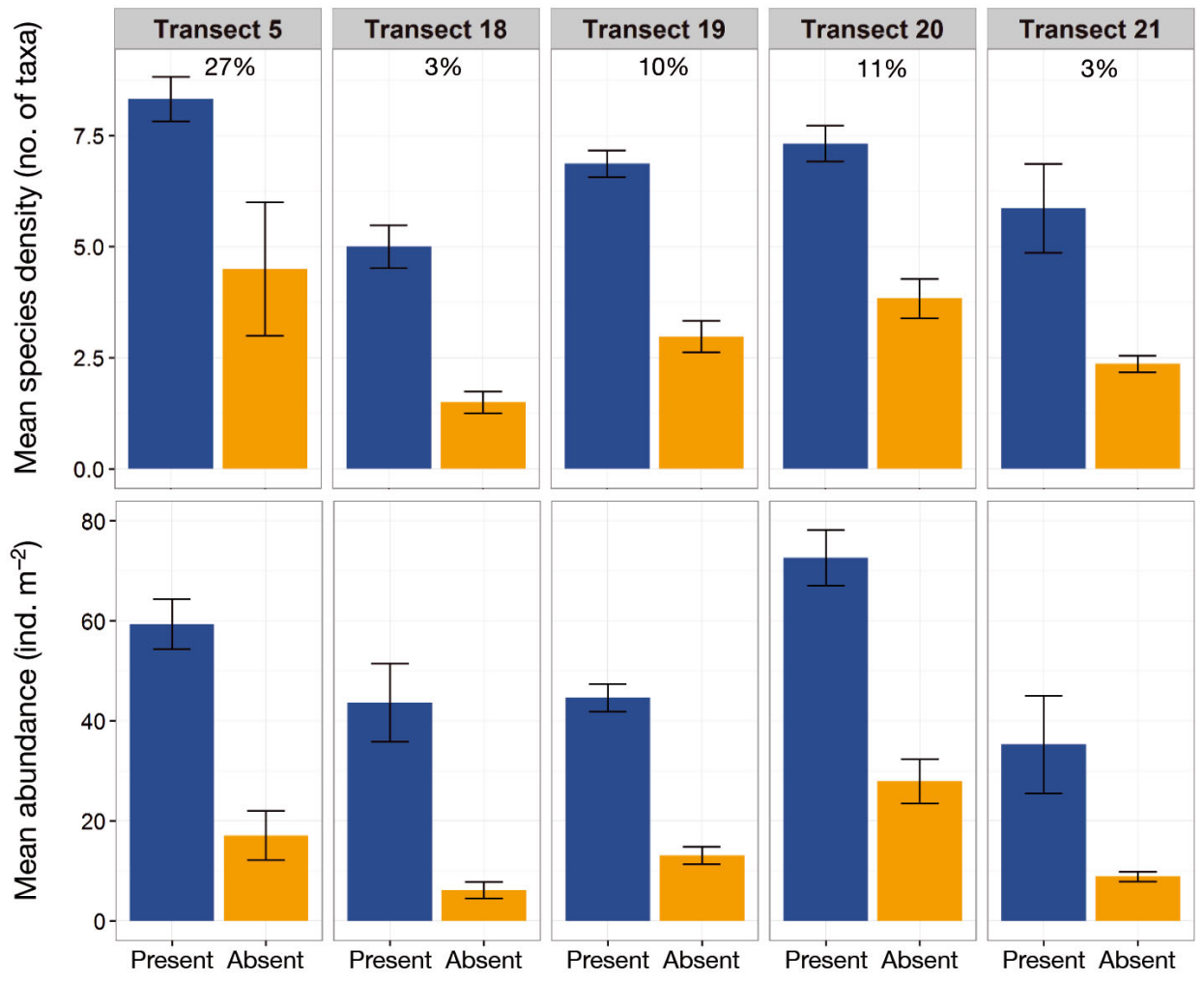

Fig. 4. Mean species density and abundance of epibenthic megafauna in photos with $\mathrm{Va}$ zella pourtalesi present and absent, across each of the 5 photo-transects. Error bars indicate standard error. Mean percent cover of hard substrate per transect is indicated at the top of each panel

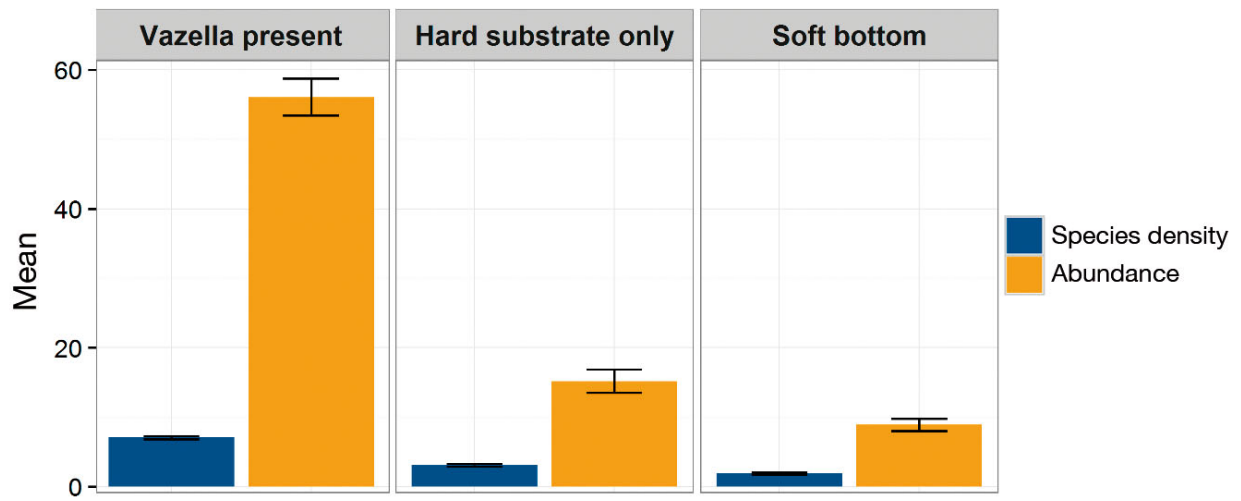

Fig. 5. Mean species density (no. of taxa) and abundance (ind. $\mathrm{m}^{-2}$ ) of epibenthic megafauna in photos with Vazella pourtalesi present (on hard substrate), photos without $V$. pourtalesi but with hard substrate, and photos taken on soft bottom without $V$. pourtalesi or hard substrate. Error bars are standard error

gesting a strong effect of the sponge on the associated megafaunal community (Fig. 5). SIMPER (results not shown) revealed that the top contributing taxa to the dissimilarity between photos with $V$. pourtalesi present and those with only hard substrate were anemones (Actiniaria spp.), sponges, and other fauna that attach to hard substrate.

\subsection{Influence of $V$. pourtalesi on trawl-caught fish and megafaunal invertebrate composition}

Community structure based on the abundance of trawl-caught fish and invertebrate species differed significantly between years and between catches with $V$. pourtalesi present or absent, with more of the dissimilarity explained by Vazella Presence/Absence than by Year (Table 6). The average similarity was similar among catches with $V$. pourtalesi present (38.65\%, Table 7) and absent (39.64\%) (withingroup similarity for catches without $V$. pourtalesi not shown), with 14 species contributing to $90 \%$ of the similarity in catches with $V$. pourtalesi. Silver hake Merluccius bilinearis accounted for $22 \%$ of the similarity between catches where $V$. pourtalesi was present, followed by redfish (Sebastes spp.), haddock Melanogrammus aeglefinus, and northern shortfin squid Illex illecebrosus (Table 7). 
Table 6. ANOSIM results from a 2-way crossed analysis testing the effects of Year and Vazella Presence/Absence on fish and megafaunal invertebrate community structure. Global R-values represent the overall significance of the test for either Vazella Presence/Absence or Year

\begin{tabular}{|lccc|}
\hline Analysis & Factor & Global R & $\mathrm{p}$ \\
\hline Two-way crossed & Year & 0.066 & 0.001 \\
& Vazella Presence/ & 0.135 & 0.001 \\
& Absence & & \\
\hline
\end{tabular}

The average dissimilarity between catches with and without $V$. pourtalesi was $61.80 \%$, with 9 species contributing to $\sim 50 \%$ of that dissimilarity, 18 species to $70 \%$, and 34 species to $90 \%$ (Table 8 ). All taxa were present in catches with and without $V$. pourtalesi; therefore, the dissimilarity between the 2 was driven by differences in their relative abundances creating dissimilar communities. Of the 9 species contributing most to this dissimilarity, pink shrimp Pandalus montagui, northern shortfin squid, Atlantic herring Clupea harengus, and haddock had higher average abundances in catches with $V$. pourtalesi. However, redfish and pollock Pollachius virens had higher average abundances in catches without $V$. pourtalesi (Table 8).

Only 4 taxa could be conclusively related between the trawl survey catch and the in situ photos: redfish, pollock, cod Gadus morhua, and the rock crab Cancer borealis. Unknown and possibly multiple species of pandalid shrimp were recorded from the photos that are likely Pandalus montagui, which was identi- fied in the catch data. The poor relatability between these data sets is likely due to a combination of different rates of detection, or 'catchability' between trawl and camera surveys, and the limited taxonomic resolution of the identifications from the in situ imagery. This supports the use of both gear types for the examination of the communities associated with $V$. pourtalesi, and the need to use different scales of resolution to sample large and mobile fauna.

\section{DISCUSSION}

Through the analyses of in situ photographs collected in Emerald Basin off Nova Scotia, Canada, we show that the monospecific sponge grounds formed by the glass sponge Vazella pourtalesi are host to a more diverse and abundant epibenthic megafaunal community compared to areas without this structureforming species. Although previous studies have shown enhanced biodiversity due to the presence of glass sponges, these were focused on the macrofaunal community associated with spicule mats (Rice et al. 1990, Bett \& Rice 1992), the role of stalked species as attachment substrate (Beaulieu 2001), or the diversity associated with sponge reefs (Chu \& Leys 2010, Dunham et al. 2018). To our knowledge, ours is the first study to examine the diversity and abundance of megafauna associated with aggregations of large, massive barrel- or vase-shaped glass sponges.

Enhanced diversity and abundance of megafauna has been associated with the mixed-species sponge

Table 7. Similarity percentage (SIMPER) analyses identifying the percent contribution of each species to the Bray-Curtis similarity metric based on transformed abundance $\left(\log _{10}(x+1)\right)$ of catches with Vazella pourtalesi. Species contributing to $90 \%$ of the total similarity are listed. Average similarity $=38.65 \%$

\begin{tabular}{|llcccc|}
\hline Species & Common name & $\begin{array}{c}\text { Mean } \\
\text { abundance }\end{array}$ & $\begin{array}{c}\text { Mean } \\
\text { similarity }\end{array}$ & $\begin{array}{c}\text { Percent contri- } \\
\text { bution to overall } \\
\text { similarity }\end{array}$ & $\begin{array}{c}\text { Cumulative percent } \\
\text { contribution to } \\
\text { overall similarity }\end{array}$ \\
\hline Merluccius bilinearis & Silver hake & 3.74 & 8.51 & 22.03 & 22.03 \\
Sebastes spp. & Redfish & 2.98 & 5.29 & 13.69 & 35.72 \\
Melanogrammus aeglefinus & Haddock & 2.32 & 5.04 & 13.04 & 48.76 \\
Illex illecebrosus & Northern shortfin squid & 2.18 & 3.97 & 10.27 & 59.03 \\
Pandalus montagui & Pink shrimp & 2.47 & 3.51 & 9.08 & 68.11 \\
Clupea harengus & Atlantic herring & 1.82 & 2.68 & 6.93 & 75.04 \\
Urophycis chuss & Red hake & 1.13 & 1.42 & 3.68 & 78.72 \\
Urophycis tenuis & White hake & 0.87 & 1.17 & 3.02 & 81.74 \\
Cancer borealis & Jonah crab & 0.61 & 0.84 & 2.18 & 83.93 \\
Squalus acanthias & Spiny dogfish & 0.94 & 0.77 & 2.00 & 85.93 \\
Pollachius virens & Pollock & 0.80 & 0.66 & 1.71 & 87.63 \\
Helicolenus dactylopterus & Blackbelly rosefish & 0.69 & 0.45 & 1.17 & 88.81 \\
Asterias rubens & Common sea star & 0.59 & 0.45 & 1.17 & 89.97 \\
Scomber scombrus & Atlantic mackerel & 0.56 & 0.39 & 1.00 & 90.97 \\
\hline
\end{tabular}


Table 8. Similarity percentage (SIMPER) analyses identifying the percent contribution of each species to the Bray-Curtis dissimilarity metric based on transformed abundance $\left(\log _{10}(x+1)\right)$ between catches with and without Vazella pourtalesi. Species contributing to $90 \%$ of the total dissimilarity are listed. Average dissimilarity $=61.80 \%$

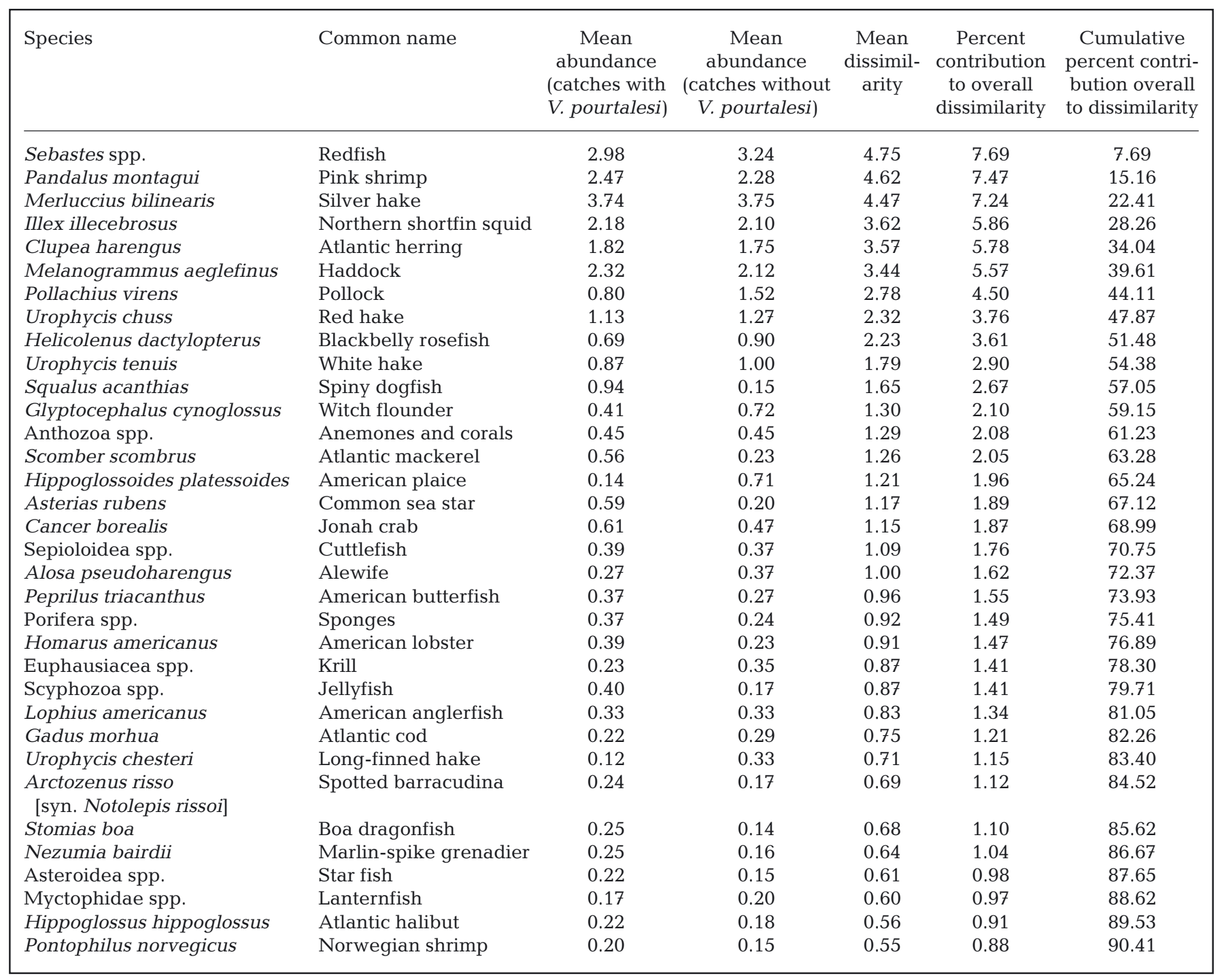

grounds of the Flemish Pass (Beazley et al. 2013), consisting of tetractinellid sponges and various other structure-forming species (e.g. glass sponge Asconema foliatum), and the tetractinellid grounds of the Sackville Spur (Beazley et al. 2015). The gear types and analytical approaches used there were similar to those employed in this study, allowing for a direct comparison of the diversity indices between sponge grounds. Examination of mean species density and abundance (standardized to $\mathrm{m}^{-2}$ ) of epibenthic megafauna across all 3 sponge grounds (Fig. 6A,B) revealed a more diverse and abundant epibenthic assemblage associated with those sponge grounds in the Flemish Pass and Sackville Spur than the mono- specific sponge grounds of $V$. pourtalesi on the Scotian Shelf. However, this appears to be the result of an overall higher diversity of megafauna on the Flemish Cap compared to the Scotian Shelf, regardless of the presence of structure-forming sponges.

It has long been recognized that the water mass properties of Emerald Basin are different compared to the surrounding shelf due to the ingression of Warm Slope Water, a warm and saline water mass originating from the Gulf Stream (Hachey 1937, McLellan et al. 1953). Through molecular and morphological analyses of polychaetes, Neal et al. (2018) tested the hypothesis that Emerald Basin represents a possible location for 'deep-water emergence,' a 

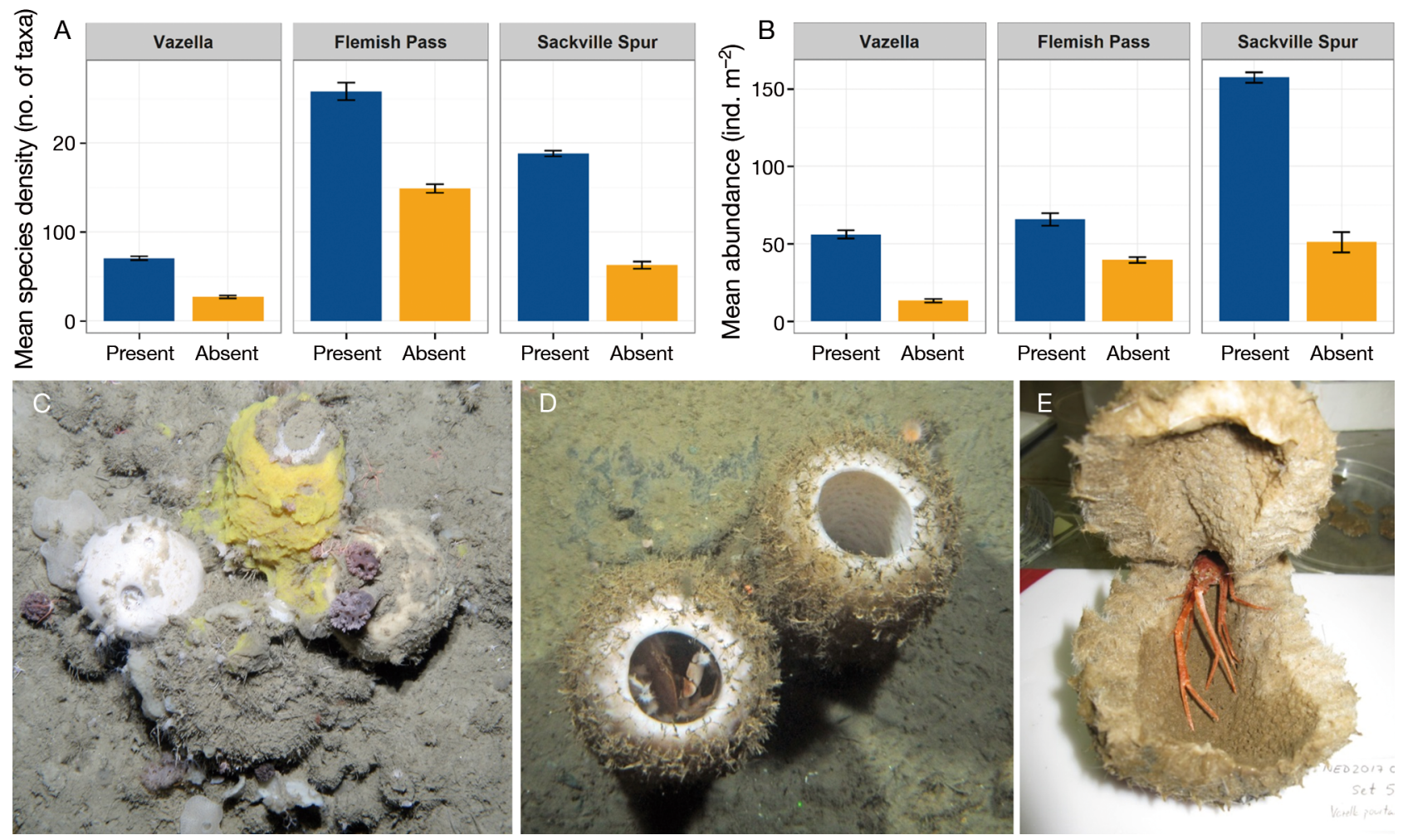

Fig. 6. Comparison of (A) mean species density and (B) standardized abundance (to $\mathrm{m}^{-2}$ ) of megafauna in photos with the presence or absence of 3 different sponge ground assemblages: Vazella pourtalesi off Nova Scotia (this study), structure-forming sponges from the mixed sponge ground assemblage from the Flemish Pass (Beazley et al. 2013), and the sponge grounds formed by tetractinellid sponges on the Sackville Spur (Beazley et al. 2015). From each sponge ground, taxon abundance data were extracted from the full community. (C) Representation of the various structure-forming tetractinellid sponges and their epifauna from the Sackville Spur (Fig. 9 in Beazley et al. 2015). (D) A crab (Cancer borealis) inside V. pourtalesi from images collected for this study. (E) Munida iris crustacean found inside $V$. pourtalesi sponge collected from the multispecies trawl survey. This species was not observed in the in situ imagery. Error bars are standard error (SE)

phenomenon whereby the environmental conditions and thus benthic fauna are more similar to those that characterize deeper depths, and found species with shared commonalities to those in the deep North Sea and/or northeast Atlantic. The unique water mass properties of Emerald Basin likely negate any direct comparison of the composition and diversity of fauna between the sponge grounds that reside there and those of the Flemish Cap, where sponge grounds have been reported at much colder temperatures $\left(<4.5^{\circ} \mathrm{C}\right)$ due to the influence of cold and fresh Labrador Sea Water (Murillo et al. 2012, Beazley et al. 2015; although see Beazley et al. 2015 for links between Sackville Spur sponge grounds and the warmer Irminger Current). Nonetheless, the relative difference in mean species density between photos with and without $V$. pourtalesi (2.6 times higher in photos with $V$. pourtalesi) was comparable to that of the Sackville Spur sponge grounds where species density was 3 times higher in photos with structureforming sponges than without, and was higher than that of the Flemish Pass sponge grounds (1.8 times).
For mean abundance, this difference was greatest in the $V$. pourtalesi sponge grounds (4.2 times higher in photos with $V$. pourtalesi than without, compared to 3.1 and 1.6 times for the Sackville Spur and Flemish Pass sponge grounds, respectively), suggesting a strong influence of the sponge grounds formed by $V$. pourtalesi on the structure, diversity and abundance of epibenthos in Emerald Basin.

We also observed notable differences in the role of habitat provision between the mixed-species tetractinellid sponges of the Flemish Cap and the monospecific sponge grounds of the Scotian Shelf, which may influence their associated biodiversity and faunal composition. For instance, the larger tetractinellid sponges on the Sackville Spur often acted as attachment substrate for other taxa such as encrusting sponges and soft corals (Fig. 6C; Beazley et al. 2015), an observation also reported by Klitgaard (1995) in a study of the fauna associated with 'ostur' sponges of the Faroe Islands. This phenomenon was not observed in the sponge grounds formed by $V$. pourtalesi, where only a few taxa (mainly ophiuroids) 
were found on the surface of the sponges themselves. The absence of epifauna on $V$. pourtalesi may be due to strong anti-fouling properties as observed in some tetractinellid species (Sjögren et al. 2011), to its surface texture and the absence of spicule 'fur' (Klitgaard 1995), or the presence of long siliceous spicules, which can project from the dermal surface of $V$. pourtalesi by over $5 \mathrm{~cm}$ (Tabachnik 2002), possibly inhibiting the settlement or attachment of other fauna. In contrast, the vase shape of $V$. pourtalesi appeared to provide a unique niche for megafauna, as motile fauna such as rock crabs and redfish were sometimes observed inside the barrel-shaped sponge itself (Fig. 6D,E), possibly using the structure as a refuge from predators. This diversity likely goes largely uncaptured in in situ camera surveys, being only effectively observed through collection of the sponge itself. Specimens of $V$. pourtalesi collected in the DFO multispecies bottom-trawl survey corroborate this, as motile crustaceans and other fauna were often discovered inside the sponges upon physical examination (Fig. 6E).

Unlike the tetractinellid sponge grounds of the Flemish Cap, which primarily settle on soft sandy/ muddy substrate with few cobbles and boulders, $V$. pourtalesi settles on hard substrate, which has also shown to increase habitat complexity and enhance the diversity of local fauna (Lacharité \& Metaxas 2017). The presence of $V$. pourtalesi and percent cover of hard substrate were both statistically significant predictors of species density and abundance. However, both of these factors were confounded with one another, and the interaction between hard substrate and the presence of $V$. pourtalesi was also significant, suggesting that it cannot be statistically assessed independently from that of $V$. pourtalesi and vice versa. In this study, species density and abundance of megafauna was over 2 and 3 times higher, respectively, in photos with both hard substrate and $V$. pourtalesi than those with hard substrate alone (Fig. 5), suggesting a strong effect of the sponges on local species density and abundance of megafauna. However, photos with $V$. pourtalesi had over 6 times the amount of hard substrate than those of hard substrate alone (mean \pm SD percent cover $=14.902 \pm$ $11.261 \%$ in photos with $V$. pourtalesi vs. $2.444 \pm$ $5.047 \%$ in photos with hard substrate only), suggesting that the increased species density and abundance within the sponge grounds may be due in part to the higher proportion of hard substrate on the seabed and increased attachment substrate. If this was the case, one would expect a similar species composition between photos with $V$. pourtalesi present and those with hard substrate only. The SIMPER routine (not shown) indicated that the top contributing taxa to the dissimilarity between photos with hard substrate alone and those with $V$. pourtalesi were anemones, sponges, and other fauna that attach to pebbles, cobbles, and boulders. These fauna were also present in photos with hard substrate only but at lower abundances. However, 25 taxa were observed in photos with $V$. pourtalesi present that were not found in areas with hard substrate only. This included motile species such as redfish, the brittle star Ophiopholis aculeata, and sea stars, the latter of which typified bottom-trawl catches containing $V$. pourtalesi.

While disentangling the effects of the sponge from those of the substrate on which it settles is important for understanding the role these organisms play in the provision of habitat, the sponge grounds of Emerald Basin are defined by both the sponge itself and its geologic habitat. The mechanism of enhanced diversity and abundance of epifauna within the sponge grounds is likely due to the combined effect of both the sponge and the hard substrate on which it settles. Considering that those areas with only hard substrate are interspersed throughout the sponge grounds suggests that the presence of $V$. pourtalesi is a strong structuring agent of the epibenthos that acts across micro-scales (10s of meters). The enhanced diversity and abundance of epibenthos in the presence of $V$. pourtalesi could possibly be due to micro-scale baffling of currents and entrapment of sediments (Krautter et al. 2006, Schlacher et al. 2007), which may concentrate food resources and promote the retention of larvae. Studies to empirically measure the ability of these sponge grounds to baffle currents and enhance food supply would provide further insight into the mechanism for the enhanced biodiversity of these ecosystems.

Although the fish and megafaunal invertebrate community collected in the multispecies research vessel trawl survey differed significantly between catches with and without $V$. pourtalesi, the species that contributed most to that dissimilarity were present in both areas, differing only in relative abundance. This is not unexpected given that most species are highly mobile and none, to our knowledge, have obligate associations with the sponge. A similar result was found over the sponge grounds in Flemish Pass and along the Nose and Tail of Grand Bank (Kenchington et al. 2013), where shortnose snipe eel Serrivomer beanii, deep-sea cat shark Apristurus profundorum, and eelpout Lycodes spp., were strongly associated with the sponge grounds there but not exclusively so. There, dissimilarity between 
catches with low and high biomass of sponge was $10-20 \%$ less than reported here, while the similarity within groups was $\sim 10 \%$ higher, likely due in part to the depth range. In our study, all of the benthic invertebrates analyzed in the trawl catches (Cancer borealis, Asterias rubens, Asteroidea spp., Porifera spp., Homarus americanus) were more abundant in catches with $V$. pourtalesi, and given their poor catchability with trawl gear their abundance is likely more pronounced in situ than indicated here. Northern shortfin squid, which were also more abundant in catches with $V$. pourtalesi, are associated with the sea floor where they sometimes aggregate (Barratt \& Allcock 2014). During the summer, some squid follow shoals of fish inshore (O'Dor \& Dawe 1998), and the high catches of mackerel (Scomber scombrus), also more abundant in catches with $V$. pourtalesi, could also account for the higher presence of squid there.

Our quantitative analysis puts into perspective the study of Fuller (2011), who documented associations between Sebastes redfish and pollock and the sponge grounds. We show that although those species are found in the sponge grounds, their mean abundance is higher outside of the sponges grounds (Table 8). This is more pronounced for pollock than redfish, although both contribute to the overall community similarity of catches with $V$. pourtalesi (Table 7), an association also noted by Fuller (2011). Silver hake, the species most typical of catches with V. pourtalesi, is a bentho-pelagic species associated with water temperatures of $7-10^{\circ} \mathrm{C}$ (Carpenter 2015), which typify the sponge grounds in Emerald Basin. Juvenile silver hake feed on crustaceans (euphausiids and pandalids), while the larger size class ( $\geq 40 \mathrm{~cm}$ total length) is piscivorous, feeding on clupeids such as Scomber scombrus, Urophycis chuss, and Gadus morhua (Lloris et al. 2005). Both pandalids and the clupeid Scomber scombrus were more abundant in catches with $V$. pourtalesi, suggesting that some fish associated with $V$. pourtalesi may be using the sponge grounds to feed.

In conclusion, we have demonstrated that the sponge grounds formed by $V$. pourtalesi on the Scotian Shelf enhance biodiversity of benthic epifauna and are used by a distinct (based on abundance) fish community. While the presence of hard substrate in the sponge grounds enables colonization by $V$. pourtalesi and introduces habitat heterogeneity and thereby diversity, the sponges themselves further enhance diversity, potentially through habitat modification. Further research into the physiology and ecology of $V$. pourtalesi in this area may elucidate the mechanisms which promote the observed patterns of diversity.
Acknowledgements. This work was funded in part through the SponGES - Deep-sea Sponge Grounds Ecosystems of the North Atlantic: an integrated approach towards their preservation and sustainable exploitation, under H2020 the EU Framework Programme for Research and Innovation (Grant Agreement no. 679849) where Fisheries and Oceans Canada (DFO) is a third-party participant. This research was funded in part through the DFO Strategic Program for Ecosystem-Based Research and Advice (SPERA) project 'Evaluation of the Effectiveness of Two Sponge Conservation Areas in the Maritimes Region: Identifying Patterns of Dispersal, Connectivity, and Recovery Potential of the Russian Hat Sponge Vazella pourtalesi' led by L. Beazley. We thank C. Lirette (DFO) for the extraction and preparation of data from the multispecies trawl survey database, and Dr. F.J. Murillo and Dr. R. Stanley (DFO) for providing comments on an earlier version of this manuscript.

\section{LITERATURE CITED}

Barratt I, Allcock L (2014) Illex illecebrosus. The IUCN Red List of Threatened Species 2014: e.T163002A962911. http://dx.doi.org/10.2305/IUCN.UK.2014-1.RLTS.T163002 A962911.en.

* Barthel D, Tendal OS, Thiel H (1996) A wandering population of the hexactinellid sponge Pheronema carpenteri on the continental slope off Morocco, Northwest Africa. Mar Ecol 17:603-616

Beaulieu SE (2001) Life on glass houses: sponge stalk communities in the deep sea. Mar Biol 138:803-817

Beazley LI, Kenchington EL (2015) Epibenthic megafauna of the Flemish Pass and Sackville Spur (Northwest Atlantic) identified from in situ benthic image transects. Can Tech Rep Fish Aquat Sci 3127: v + 496 p

Beazley LI, Kenchington EL, Murillo FJ, Sacau M (2013) Deep-sea sponge grounds enhance diversity and abundance of epibenthic megafauna in the Northwest Atlantic. ICES J Mar Sci 70:1471-1490

* Beazley L, Kenchington E, Yashayaev I, Murillo FJ (2015) Drivers of epibenthic megafaunal composition in the sponge grounds of the Sackville Spur, northwest Atlantic. Deep-Sea Res I 98:102-114

Beazley L, Wang Z, Kenchington E, Yashayaev I and others (2018) Predicted distribution of the glass sponge Vazella pourtalesi on the Scotian Shelf and persistence in the face of climatic variability. PLOS ONE 13:e0205505

Bell JJ (2008) The functional roles of marine sponges. Estuar Coast Shelf Sci 79:341-353

* Bett BJ, Rice AL (1992) The influence of hexactinellid sponge (Pheronema carpenteri) spicules on the patchy distribution of macrobenthos in the Porcupine Seabight (bathyal NE Atlantic). Ophelia 36:217-226

Bo M, Bertolino M, Bravestrello G, Canese S and others (2012) Role of deep sponge grounds in the Mediterranean Sea: a case study in southern Italy. Hydrobiologia 687:163-177

Boury-Esnault N, Rützler K (eds) (1997) Thesaurus of sponge morphology. Smithson Contrib Zool 596:1-55

Carpenter KE (2015) Merluccius bilinearis. The IUCN Red List of Threatened Species 2015: e.T16466393A16509787. http://dx.doi.org/10.2305/IUCN.UK.2015-4.RLTS.T1646 6393A16509787.en (accessed 2 August 2018)

Chadwick EMP, Brodie W, Colbourne E, Clark D, Gascon D, Hurlbut T (2007) History of annual multi-species trawl 
surveys on the Atlantic Coast of Canada. AZMP Bull 6: 25-42

* Chu JWF, Leys SP (2010) High resolution mapping of community structure in three glass sponge reefs (Porifera, Hexactinellida). Mar Ecol Prog Ser 417:97-113

Clarke KR, Gorley RN (2006) PRIMER v6: User Manual/ Tutorial (Plymouth Routines in Multivariate Ecological Research). PRIMER-E, Plymouth

Clarke KR, Warwick RM (2001) Change in marine communities: an approach to statistical analysis and interpretation, 2nd edn. PRIMER-E, Plymouth

Dunham A, Archer SK, Davies SC, Burke LA, Mossman J, Pegg JR, Archer E (2018) Assessing condition and ecological role of deep-water biogenic habitats: glass sponge reefs in the Salish Sea. Mar Environ Res 141:88-99

Fortin MJ, Dale MRT (2005) Spatial analysis: a guide for ecologists. Cambridge University Press, Cambridge

Freese JL, Wing BL (2003) Juvenile red rockfish, Sebastes sp., associations with sponges in the Gulf of Alaska. Mar Fish Rev 65:38-42

Fuller SD (2011) Diversity of marine sponges in the Northwest Atlantic. PhD dissertation, Dalhousie University, Halifax

Gotelli NJ, Colwell RK (2011) Estimating species richness. In: Magurran AE, McGill BJ (eds) Biological diversity: frontiers in measurement and assessment. Oxford University Press, Oxford, p 39-54

*Hachey HB (1937) The submarine physiography and oceanographical problems of the Scotian Shelf. Trans Am Fish Soc 66:237-241

Hogg MM, Tendal OS, Conway KW, Pomponi SA and others (2010) Deep-sea sponge grounds: reservoirs of biodiversity. UNEP-WCMC Biodiv Ser No 32. UNEP-WCMC, Cambridge

Jones CG, Lawton JH, Shachak M (1994) Organisms as ecosystem engineers. Oikos 69:373-386

Kenchington E, Power D, Koen-Alonso M (2013) Associations of demersal fish with sponge grounds on the continental slopes of the northwest Atlantic. Mar Ecol Prog Ser 477:217-230

Kenchington TJ, Kenchington ELR (2013) Biodiversity metrics for use in the ecosystem approach to oceans management. Can Tech Rep Fish Aquat Sci 3059: vi + 188 p

Klitgaard AB (1995) The fauna associated with outer shelf and upper slope sponges (Porifera, Demospongiae) at the Faroe Islands, Northeastern Atlantic. Sarsia 80:1-22

Klitgaard AB, Tendal OS (2004) Distribution and species composition of mass occurrences of large-sized sponges in the northeast Atlantic. Prog Oceanogr 61:57-98

Knudby A, Kenchington E, Murillo FJ (2013) Modeling the distribution of Geodia sponges and sponge grounds in the northwest Atlantic Ocean. PLOS ONE 8:e82306

Krautter M, Conway KW, Barrie JV (2006) Recent hexactinosidan sponge reefs (silicate mounds) off British Columbia, Canada: frame-building processes. J Paleontol 80:38-48

Kühn I (2007) Incorporating spatial autocorrelation may invert observed patterns. Divers Distrib 13:66-69

Kutti T, Bannister RJ, Fosså JH (2013) Community structure and ecological function of deep-water sponge grounds in the Traenadypet MPA - Northern Norwegian continental shelf. Cont Shelf Res 69:21-30

Lacharité M, Metaxas A (2017) Hard substrate in the deep ocean: how sediment features influence epibenthic megafauna on the eastern Canadian margin. Deep-Sea Res I 126:50-61
Legendre P, Legendre L (1998) Numerical ecology, 2nd English edn. Elsevier, Amsterdam

* Legendre P, Dale MRT, Fortin MJ, Gurevitch J, Hohn M, Myers D (2002) The consequences of spatial structure for the design and analysis of ecological field surveys. Ecography 25:601-615

Lloris D, Matallanas J, Oliver P (2005) Hakes of the world. Food and Agricultural Organization of the World, Rome

Maldonado M, Aguilar R, Bannister RJ, Bell JJ and others (2017) Sponge grounds as key marine habitats: a synthetic review of types, structure, functional roles, and conservation concerns. In: Rossi S, Bramanti L, Gori A, Orejas C (eds) Marine animal forests. Springer International Publishing, Cham, p 143-183

*Marliave JB, Conway KW, Gibbs DM, Lamb A, Gibbs C (2009) Biodiversity and rockfish recruitment in sponge gardens and bioherms of southern British Columbia, Canada. Mar Biol 156:2247-2254

*McLellan HJ, Lauzier L, Bailey WB (1953) The slope water off the Scotian Shelf. J Fish Res Board Can 10:155-176

* Miller RJ, Hocevar J, Stone RP, Fedorov DV (2012) Structure-forming corals and sponges and their use as fish habitat in Bering Sea submarine canyons. PLOS ONE 7: e33885

*Murillo FJ, Durán Muñoz P, Cristobo J, Ríos P, González C, Kenchington E, Serrano A (2012) Deep-sea sponge grounds of the Flemish Cap, Flemish Pass, and the Grand Banks of Newfoundland (Northwest Atlantic Ocean): distribution and species composition. Mar Biol Res 8:842-854

*Neal L, Taboada S, Woodall LC (2018) Slope-shelf faunal link and unreported diversity off Nova Scotia: evidence from polychaete data. Deep-Sea Res I 138:72-84

O'Dor RK, Dawe EG (1998) Illex illecebrosus. In: Rodhouse PG, Dawe EG, O'Dor RK (eds) Squid recruitment dynamics. The genus Illex as a model. The commercial Illex species. Influences on variability. FAO Fish Tech Pap No. 376. FAO, Rome

* Onsrud MSR, Kaartvedt S (1998) Diel vertical migration of the krill Meganyctiphanes norvegica in relation to physical environment, food and predators. Mar Ecol Prog Ser 171:209-219

R Core Team (2016) R: a language and environment for statistical computing. R Foundation for Statistical Computing, Vienna

Reiswig HM (1996) Redescription and placement of the rossellid genus Vazella Gray (Hexactinellida: Lyssacinosida). Bull Inst R Sci Nat Belg 66(Suppl):135-141

Reiswig H (2006) Classification and phylogeny of Hexactinellida (Porifera). Can J Zool 84:195-204

* Rice AL, Thurston MH, New AL (1990) Dense aggregations of a hexactinellid sponge, Pheronema carpenteri, in the Porcupine Seabight (northeast Atlantic Ocean), and possible causes. Prog Oceanogr 24:179-196

Roberts EM, Mienis F, Rapp HT, Hanz U, Meyer HK, Davis AJ (2018) Oceanographic setting and short timescale environmental variability at an Arctic seamount sponge ground. Deep-Sea Res I 138:98-113

* Schlacher TA, Schlacher-Hoenlinger MA, Williams A, Althaus F, Hooper JNA, Kloser R (2007) Richness and distribution of sponge megabenthos in continental margin canyons off southeastern Australia. Mar Ecol Prog Ser 340:73-88

* Schneider DC, Gagnon JM, Gilkinson KD (1987) Patchiness of epibenthic megafauna on the outer Grand Banks of Newfoundland. Mar Ecol Prog Ser 39:1-13 
Sjögren M, Jonsson PR, Dahlström M, Lundälv T, Burman R, Göransson U, Bohlin L (2011) Two brominated cyclic dipeptides released by the coldwater marine sponge Geodia barretti act in synergy as chemical defense. J Nat Prod 74:449-454

Tabachnik KR (2002) Rossellidae Schulze, 1885. In: Hooper JNA, Van Soest RWM (eds) Systema Porifera: a guide to the classification of sponges. Kluwer Academic/Plenum Publishers, New York, NY, p 1441-1504

Tremblay MJ, Black GAP, Branton RM (2007) The distribution of common decapod crustaceans and other invertebrates recorded in annual ecosystem surveys of the Scotian Shelf 1999-2006. Can Tech Rep Fish Aquat Sci 2762: iii $+74 \mathrm{p}$

Editorial responsibility: James McClintock, Birmingham, Alabama, USA
UNGA (United Nations General Assembly) (2006) Sustainable fisheries, including through the 1995 Agreement for the Implementation of the Provisions of the United Nations Convention on the Law of the Sea of 10 December 1982 relating to the Conservation and Management of Straddling Fish Stocks and Highly Migratory Fish Stocks, and related instruments. A/ RES/61/105. www.un.org/depts/los/general_assembly/ general_assembly_resolutions.htm (accessed 26 June 2018)

Zuur AF, Ieno EN, Walker NJ, Saveliev AA, Smith GM (2009) Mixed effects models and extensions in Ecology with R. Springer Science+Business Media, Berlin

Submitted: October 29, 2018; Accepted: February 19, 2019 Proofs received from author(s): March 22, 2019 